\title{
HBT1, a Novel AMPA Receptor Potentiator with Lower Agonistic Effect, Avoided Bell-Shaped Response in In Vitro BDNF Production $\mathbf{s}$
}

\author{
Akiyoshi Kunugi, Yasukazu Tajima, Haruhiko Kuno, Satoshi Sogabe, and Haruhide Kimura \\ Research, Takeda Pharmaceutical Company Limited, Fujisawa, Kanagawa, Japan
}

Received September 11, 2017; accepted December 28, 2017

\begin{abstract}
$\alpha$-Amino-3-hydroxy-5-methyl-4-isoxazole-propionic acid (AMPA) receptor (AMPA-R) potentiators with brain-derived neurotrophic factor (BDNF)-induction potential could be promising as therapeutic drugs for neuropsychiatric and neurologic disorders. However, AMPA-R potentiators such as LY451646 have risks of narrow bell-shaped responses in pharmacological effects, including in vivo BDNF induction. Interestingly, LY451646 and LY451395, other AMPA-R potentiators, showed agonistic effects and exhibited bell-shaped responses in the BDNF production in primary neurons. We hypothesized that the agonistic property is related to the bell-shaped response and endeavored to discover novel AMPA-R potentiators with lower agonistic effects. LY451395 showed an agonistic effect in primary neurons, but not in a cell line expressing AMPA-Rs, in $\mathrm{Ca}^{2+}$ influx assays; thus, we used a $\mathrm{Ca}^{2+}$ influx assay in primary neurons and, from a chemical library, discovered two AMPA-R potentiators with lower
\end{abstract}

agonistic effects: 2-(((5-methyl-3-(trifluoromethyl)-1H-pyrazol-1-yl)acetyl)amino)-4,5,6,7-tetrahydro-1-benzothiophene-3-carboxamide (HBT1) and (3S)-1-(4-tert-butylphenyl)-N-((1R)-2-(dimethylamino)-1phenylethyl)-3-isobutyl-2-oxopyrrolidine-3-carboxamide (OXP1). In a patch-clamp study using primary neurons, HBT1 showed little agonistic effect, whereas both LY451395 and OXP1 showed remarkable agonistic effects. HBT1, but not OXP1, did not show remarkable bell-shaped response in BDNF production in primary neurons. HBT1 bound to the ligand-binding domain (LBD) of AMPA-R in a glutamate-dependent manner. The mode of HBT1 and LY451395 binding to a pocket in the LBD of AMPA-R differed: HBT1, but not LY451395, formed hydrogen bonds with S518 in the LBD. OXP1 may bind to a cryptic binding pocket on AMPA-R. Lower agonistic profile of HBT1 may associate with its lower risks of bell-shaped responses in BDNF production in primary neurons.

\section{Introduction}

Accumulating lines of evidence are suggesting that dysfunction of glutamatergic signaling contributes to cognitive deficits and mood disorder. The ionotropic glutamate receptor, $\alpha$-amino-3-hydroxy-5-methyl-4-isoxazole-propionic acid (AMPA) receptor (AMPA-R), mediates the vast majority of fast excitatory neurotransmission in the central nervous system (Kew and Kemp, 2005). AMPA-Rs are composed of four subunits (GluA1-4), which have flip (i) and flop (o) splice isoforms, and native AMPA-Rs are most likely tetramers generated by the assembly of one or more of these subunits (Boulter et al., 1990; Keinanen et al., 1990; Nakanishi et al., 1990; Sommer et al., 1990; Fletcher et al., 1995). Adding to the complexity of AMPA-Rs is RNA editing of a Q/R (glutamine/ arginine) site of the GluA2 and also differential assembly with

\footnotetext{
All authors are employees of Takeda Pharmaceutical.

This work was supported by Takeda Pharmaceutical.

https://doi.org/10.1124/jpet.117.245050.

S This article has supplemental material available at jpet.aspetjournals.org.
}

auxiliary accessory transmembrane proteins such as transmembrane AMPA-R regulatory proteins (TARPs) (Schoft et al., 2007; Kato et al., 2008; Tomita, 2010). The extracellular portion of each AMPA-R subunit consists of two domains: a ligand-binding domain (LBD) and an amino-terminal domain (ATD) (Sobolevsky et al., 2009). AMPA-R plays an important role in synaptic plasticity, which is essential for learning and memory (Derkach et al., 2007). In fact, AMPA-R potentiators improved cognitive performance in multiple tasks (O'Neill and Dix, 2007; Shaffer et al., 2013). Importantly, some AMPA-R potentiators can induce production of brain-derived neurotrophic factor (BDNF) and exhibit neurotrophic and neuroprotective properties (Murray et al., 2003; O'Neill et al., 2004). As BDNF has been considered to have a role in the pathophysiology of various neuropsychiatric disorders, including depression (Balaratnasingam and Janca, 2012), AMPA-R potentiators with potential to increase BDNF levels could be promising drugs to treat neuropsychiatric and neurologic disorders (O’Neill and Witkin, 2007).

AMPA-R agonists, which can activate all AMPA-Rs, including resting receptors, have been shown to induce both

ABBREVIATIONS: AMPA, $\alpha$-amino-3-hydroxy-5-methyl-4-isoxazole-propionic acid; AMPA-R, AMPA receptor; ATD, amino-terminal domain; BDNF, brain-derived neurotrophic factor; CHO, Chinese hamster ovary; CTZ, cyclothiazide; DMSO, dimethylsulfoxide; HBT1, 2-(((5-methyl-3(trifluoromethyl)-1H-pyrazol-1-yl)acetyl)amino)-4,5,6,7-tetrahydro-1-benzothiophene-3-carboxamide; LBD, ligand-binding domain; LDH, lactate dehydrogenase; MIF, macrophage migration inhibitory factor; Ni-NTA, nickel-nitrolotriacetic acid; OXP1, (3S)-1-(4-tert-butylphenyl)-N-((1R)-2(dimethylamino)-1-phenylethyl)-3-isobutyl-2-oxopyrrolidine-3-carboxamide; PCR, polymerase chain reaction; SPA, scintillation proximity assay; TARP, transmembrane AMPA-R regulatory protein. 
desensitization of AMPA-R and seizure (Yamada, 1998; Beattie et al., 2000; Ehlers, 2000). AMPA-R potentiators are considered to have better pharmacological profiles because of their selective enhancement of physiologic activation of AMPA-Rs in the brain. However, AMPA-R potentiators such as LY451646, LY451395, and S18986 are reported to elicit bell-shaped responses in various pharmacological effects: LY451646 is reported to show bell-shaped responses in in vivo $\mathrm{BDNF}$ induction, and the bell-shaped response of LY451395 in the radial maze task was described in the introduction section of a report about LY451395 (Mackowiak et al., 2002; Bai et al., 2003; Fowler et al., 2004; Jhee et al., 2006; Bernard et al., 2010). PF-4778574 is reported to have less than a 30 -fold safety margin against seizure in rodents (Shaffer et al., 2013). Thus, discovery of AMPA-R potentiators with lower risks of these issues is needed.

In this study, we tried to understand the mechanisms of action underlying the bell-shaped response of AMPA-R potentiators. We found that both LY451646 and LY451395 started to exhibit a bellshaped response at concentrations at which they started to show agonistic effect in BDNF protein production in primary neurons. Thus, agonistic effect may be associated with the bell-shaped responses of AMPA-R potentiators. To gain more insight into this hypothesis, we conducted a high-throughput screening and discovered new AMPA-R potentiators with lower agonistic effect in $\mathrm{Ca}^{2+}$ influx assays in primary neurons, 2-(((5-methyl-3(trifluoromethyl)-1H-pyrazol-1-yl)acetyl)amino)-4,5,6,7tetrahydro-1-benzothiophene-3-carboxamide (HBT1) and (3S)-1-(4-tert-butylphenyl)-N-((1R)-2-(dimethylamino)-1phenylethyl)-3-isobutyl-2-oxopyrrolidine-3-carboxamide (OXP1). Based on careful in vitro characterization of LY451395, HBT1, and OXP1 using binding assays, cocrystallization analysis, a patch-clamp study, $\mathrm{Ca}^{2+}$ influx assays, and BDNF assay, etc., in this work we provide evidence that agonistic effects of AMPA-R potentiators may be associated with their risks of bell-shaped responses in BDNF production in primary neurons. HBT1 is shown to be a novel AMPA-R potentiator with lower agonistic effects in $\mathrm{Ca}^{2+}$ influx assay, a patch-clamp study, and BDNF assay in primary neurons, and have a lower risk of bell-shaped responses in BDNF production in primary neurons.

\section{Materials and Methods}

Chemicals. HBT1, OXP1, LY451395, and LY451646 were synthesized by Takeda Pharmaceutical. $\left[{ }^{3} \mathrm{H}\right]-\mathrm{HBT} 1$ and $\left[{ }^{3} \mathrm{H}\right]-\mathrm{OXP} 1$ were synthesized by Sekisui Medical (Tokyo, Japan). (S)-AMPA was obtained from Enzo Life Sciences (Farmingdale, NY). 2,3-Dioxo-6nitro-1,2,3,4- tetrahydrobenzo[f]quinoxaline-7-sulfonamide (NBQX) was obtained from Wako (Tokyo, Japan) or Tocris (Bristol, UK). Cyclothiazide (CTZ) was purchased from Tocris. All other materials were obtained from standard commercial sources.

Animals. Sprague-Dawley rats were supplied by Charles River Laboratories Japan (Yokohama, Japan). The animals were housed in a light-controlled room (12-hour light/dark cycle, with lights on at 7:00 AM) and were habituated more than 1 week prior to experiments. The care and use of the animals and the experimental protocols used in this research were approved by the Experimental Animal Care and Use Committee of Takeda Pharmaceutical.

Preparation of Rat Primary Neurons. Primary cultures of hippocampal neuronal cells were prepared from fetal Sprague-Dawley rats at 19 days of gestation. Rat embryos were decapitated, and their whole brains were isolated. Hippocampi were dissected in ice-cold Hanks' balanced salt solutions under a microscope and then dispersed into cells using a neural cell dispersion kit (Sumitomo Bakelite, Tokyo, Japan). The dissociated cells were suspended in Neurobasal medium containing B27 supplement (Thermo Fisher Scientific, Waltham, MA), $2 \mathrm{mM}$ L-glutamine (Lonza, Basel, Switzerland), $100 \mathrm{U} / \mathrm{ml}$ penicillin (Lonza), $100 \mu \mathrm{g} / \mathrm{ml}$ streptomycin (Lonza), and $20 \mu \mathrm{g} / \mathrm{ml}$ gentamicin sulfate (Lonza). The cells were plated on poly-D-lysine-coated 96-well plates (Corning, Corning, NY) for $\mathrm{Ca}^{2+}$ influx assay or poly-Llysine-coated 96-well plates (Sumitomo Bakelite) for other experiments at a density of $5 \times 10^{4}$ cells/well and cultured in a humidified $\mathrm{CO}_{2}$ incubator with $5 \% \mathrm{CO}_{2}$ at $37^{\circ} \mathrm{C}$.

BDNF Assay in Primary Neurons. After 5 days of culture, the cells were used for the BDNF assay. Primary cultures of hippocampal neuronal cells were treated with compounds in the presence or absence of AMPA $(1 \mu \mathrm{M})$ and cultured in a humidified $\mathrm{CO}_{2}$ incubator with $5 \% \mathrm{CO}_{2}$ at $37^{\circ} \mathrm{C}$ for 24 hours. The cells were washed once using phosphate-buffered saline and were collected using $60 \mu$ l lysis buffer [20 mM Tris- $\mathrm{HCl}$ at $\mathrm{pH} 8.0,137 \mathrm{mM} \mathrm{NaCl}, 10 \%$ glycerol, $1 \%$ Nonidet P-40, $1 \%$ protease inhibitor cocktail (Sigma-Aldrich, St. Louis, MO)]. Concentrations of BDNF were measured using a BDNF Emax ImmunoAssay System (Promega, Fitchburg, WI).

Lactate Dehydrogenase Release Assay Using Primary Neurons. After 5 days of culture, the cells were used for the lactate dehydrogenase $(\mathrm{LDH})$ release assay. Primary cultures of hippocampal neuronal cells were treated with compounds in the presence or absence of AMPA $(1 \mu \mathrm{M})$ and cultured in a humidified $\mathrm{CO}_{2}$ incubator with $5 \% \mathrm{CO}_{2}$ at $37^{\circ} \mathrm{C}$ for 24 hours. Concentrations of $\mathrm{LDH}$ in the collected culture medium were measured using a LDH cytotoxicity detection kit (Takara Bio, Kusatsu, Japan). The amount of LDH release induced by the addition of Triton X-100 (final 2\%) was defined as the maximum releasable LDH activity (100\%) in the cells.

Whole-Cell Patch-Clamp Recording Using Primary Neurons. After 11-20 days of culture, the cells were used for the whole-cell patch-clamp recording. Whole-cell patch-clamp technique was used for recording current from cultured neurons of rat hippocampus. Patch electrodes with tip resistances ranging from 3 to $5 \mathrm{M} \Omega$ were filled with an intracellular solution containing (concentrations in millimolar) $\mathrm{CsCl}$ 135.0, $\mathrm{MgCl}_{2}$ 1.0, HEPES 10.0, EGTA 10.0, Mg-ATP 4.0, and $\mathrm{Na}_{2}$-GTP 0.3 , adjusted to $\mathrm{pH} 7.3$ with $\mathrm{CsOH}$ (osmolality 275-295 mosm/l). The extracellular solution contained (concentrations in millimolar) $\mathrm{NaCl} 140.0, \mathrm{KCl} 4.0, \mathrm{CaCl}_{2} 2.0, \mathrm{MgCl}_{2} 1.0, \mathrm{HEPES}$ $10.0, \mathrm{NaHCO}_{3} 5.0, \mathrm{D}(+)$-glucose 10.0 , tetrodotoxin (TTX) 0.001 , and D-(-)-2-amino-5-phosphonopentanoic acid (D-AP5) 0.05, adjusted to $\mathrm{pH} 7.4$ with $\mathrm{NaOH}$ (osmolality $300-315 \mathrm{mosm} / \mathrm{l}$ ). All experiments were carried out at room temperature and performed using an Axopatch $1 \mathrm{~B}$ amplifier with pCLAMP 9 software or a MultiClamp 700B amplifier with pCLAMP 10 software (Molecular Devices, Sunnyvale, CA), lowpass filtered at $2 \mathrm{kHz}$, and stored on a computer hard disk for offline analysis. Neurons were voltage clamped at $-80 \mathrm{mV}$. Steady-state inward currents were evoked by the application of agonist and drug via Y-tube perfusion system. In the absence of AMPA, an AMPA-R potentiator was applied for 60 seconds. In the presence of AMPA, an AMPA-R potentiator was applied 20 seconds prior to 10 -second AMPA stimulus. Data were analyzed using Clampfit 9 or Clampfit 10 software (Molecular Devices). The current magnitudes were calculated as the percentage of maximum current or percentage of agonist control current.

$\mathbf{C a}^{2+}$ Influx Assay Using Primary Neurons. After 5 days of culture, the cells were used for the $\mathrm{Ca}^{2+}$ influx assay. After removal of culture medium, $75 \mu \mathrm{l}$ fluorescent calcium indicator dye solution (Calcium4 Assay Kit; Dojindo, Kumamoto, Japan) in $\mathrm{Ca}^{2+}$ reaction buffer (Dulbecco's modified Eagle's medium, $10 \mathrm{mM}$ HEPES, and $0.05 \%$ bovine serum albumin) containing $1.25 \mathrm{mM}$ Probenecid (Dojindo) was added, and the cells were incubated for 60 minutes in $5 \% \mathrm{CO}_{2}$ at $37^{\circ} \mathrm{C}$ and washed once using $75 \mu \mathrm{l}$ fluorescent calcium indicator dye solution. After addition of $75 \mu \mathrm{l}$ fluorescent calcium indicator dye solution to each well again, the relative increases in 
intracellular $\mathrm{Ca}^{2+}$ levels induced by compounds in the presence and absence of $5 \mu \mathrm{M}$ AMPA were monitored for 8.5 minutes using a fluorometric imaging plate reader. Activity of the compound was defined as fluorescence intensity integrated over the entire period of measurement. Intensity of $0 \%$ was defined as activity in the presence of only dimethylsulfoxide (DMSO), whereas $100 \%$ was defined as activity in the presence of $5 \mu \mathrm{M}$ AMPA and $10 \mu \mathrm{M}$ HBT1. $\mathrm{EC}_{50}$ values were calculated using logistic regression analysis.

Transfected Cell Lines. Human AMPA-Rs (GluA1-4i and GluA1-4o), human TARPs $\gamma 2$ cDNA, and kainate receptors (GluK1 and GluK2) were subcloned into pcDNA3.1(+) or pcDNA3.1(-) Zeo mammalian expression vectors (Thermo Fisher Scientific). Each of the AMPA-Rs and TARPs $\gamma 2$ expression vectors was cointroduced to Chinese hamster ovary (CHO) cells using a Gene Pulser II Electroporation System (Bio-Rad Laboratories, Hercules, CA). For kainate receptors, GluK1 or GluK2 expression vectors were introduced to $\mathrm{CHO}$ cells alone. G-418 sulfate (Wako)-resistant clones were picked, and one clone was selected finally using the $\mathrm{Ca}^{2+}$ influx assay.

$\mathrm{Ca}^{2+}$ Influx Assay Using AMPA-Rs or GluK1/2 Receptors Expressing Cell Lines. CHO cells coexpressing human AMPA-Rs (GluA1-4i and GluA1-4o) and human TARPs $\gamma 2$ or CHO cells expressing kainate receptors (GluK1 and GluK2) were plated at $3 \times$ $10^{4}$ cells/well in a 96 -well Black Clear plate (Corning) and incubated for 24 hours in $5 \% \mathrm{CO}_{2}$ at $37^{\circ} \mathrm{C}$. After removal of the culture medium, $100 \mu \mathrm{l}$ fluorescent calcium indicator dye solution (Calcium5 Assay Kit; Molecular Devices) in $\mathrm{Ca}^{2+}$ reaction buffer (Hanks' balanced salt solutions, $10 \mathrm{mM}$ HEPES, and $0.1 \%$ bovine serum albumin) containing $1.25 \mathrm{mM}$ Probenecid (Thermo Fisher Scientific) was added, and the mixture was incubated for 60 minutes in $5 \% \mathrm{CO}_{2}$ at $37^{\circ} \mathrm{C}$. After a 60-minute incubation, the cells were washed once with $100 \mu \mathrm{l} /$ well $\mathrm{Ca}^{2+}$ reaction buffer and incubated with $100 \mu \mathrm{l} /$ well fluorescent calcium indicator dye solution. This washing step was omitted in the experiments for evaluation of subunit and splice-variant selectivity of compounds. Relative increases in intracellular $\mathrm{Ca}^{2+}$ levels induced by the compounds in the presence and absence of $3 \mathrm{mM}$ glutamate were monitored for 3 minutes using a fluorometric imaging plate reader (CellLux; PerkinElmer Life and Analytical Sciences, Shelton, CT). For the GluK1/2 receptor assay, fluorescent calcium indicator dye solution that included the compounds and DMSO (defined as $0 \%$ activity) or $250 \mu \mathrm{g} / \mathrm{ml}$ concanavalin A (defined as $100 \%$ activity) was used. After a 60-minute incubation, relative increases in intracellular $\mathrm{Ca}^{2+}$ levels induced by compounds in the presence of $3 \mathrm{mM}$ glutamate were monitored for 3 minutes using a fluorometric imaging plate reader. Activity of compound was defined as the integrated value of fluorescence intensities measured at all detection points. For the AMPA-R assay with $3 \mathrm{mM}$ glutamate, $0 \%$ was defined as activity in the presence of $3 \mathrm{mM}$ glutamate and DMSO, whereas $100 \%$ was defined as activity in the presence of $3 \mathrm{mM}$ glutamate and $300 \mu \mathrm{M} \mathrm{CTZ}$ or in the presence of $3 \mathrm{mM}$ glutamate and $10 \mu \mathrm{M}$ LY451646. For the AMPA-R assay without glutamate, $0 \%$ was defined as activity in the presence of only DMSO, whereas $100 \%$ was defined as activity in the presence of $3 \mathrm{mM}$ glutamate and $300 \mu \mathrm{M} \mathrm{CTZ}$ or in the presence of $3 \mathrm{mM}$ glutamate and $10 \mu \mathrm{M}$ LY451646. For the GluK1/2 assay, $0 \%$ was defined as activity in the presence of $3 \mathrm{mM}$ glutamate and DMSO, whereas $100 \%$ was defined as activity in the presence of $3 \mathrm{mM}$ glutamate and concanavalin $\mathrm{A} . \mathrm{EC}_{50}$ values were calculated using logistic regression analysis.

Expression Vector Constructs for Recombinant Proteins. GluA2o LBD consists of residues Asn413-Lys527 and Pro653-Ser796 of the full human GluA2o subunit with a GT linker connecting Lys527 and Pro653. GluA2o cDNA was used as a template for polymerase chain reaction (PCR). Primer 1 (GCATATGCATCACCATCACCATCACACGACCGAAAACCTGTATTTTCAGGGATCCAATAAGAC TGTTGTTGTCACCACA) and primer 2 (AAGATCCTCAGCACTTTCGATGGGGGTACCCTTCTTGATCATGATAGATATCCC) were used to generate the gene fragment $\mathrm{S} 1$ (which has a NdeI site and KpnI site), and primer 3 (GGGATATCTATCATGATCAAGAAGGGTACCC CCATCGAAAGTGCTGAGGATCTT) and primer 4 (CGCGGCCGCT CAGCTGCCGCACTCTCCTTT) were used to generate the gene fragment S2 (which has a KpnI site and NotI site). The PCR products were subcloned into pCR TOPO II vector. Plasmids were digested by $\mathrm{NdeI} / \mathrm{KpnI}$ for $\mathrm{S} 1$ and $\mathrm{KpnI} / \mathrm{NotI}$ for $\mathrm{S} 2$, and they were ligated and cloned into $\mathrm{pRH} 8$ vector (which is a pRSF-1b-derived vector with a NdeI site inserted between the His6-tag region and the KpnI site).

GluA2o ATD domain gene was obtained from the hGluA2o (22-404)-His/pcDNA3.3 vector, which contains a TEV cleavage site at both the $\mathrm{N}$ terminus and $\mathrm{C}$ terminus of GluA2 ATD consisting of residues Val22-Ser404 of the full human GluA2o subunit. The hGluA2o (22-404)-His gene was generated through PCR amplification using GluA2o cDNA as a template. Primer 1 (GATGGGTTGCGTAGCTGAAGGATCCGAAAACCTGTATTTTCAGGGTGTCTCTTCTAACAGCATACAG) and primer 2 (ATAATAGCTAGCTTGGAA GTATAAATTCTCAGAAGGGAGCTCAGTAAGGGTAAC), which have a BamHI/EcoRI site and TEV cleavage site, were used as PCR primers. This plasmid was digested by BamHI/EcoRI, and the obtained GluA2o ATD gene was cloned into pSeqTag2 vector (Thermo Fisher Scientific) for addition of the human Ig $\kappa$ secretion signal sequence.

Expression and Purification of Recombinant Proteins. pRH8-GluA2-LBD plasmids were transformed in Escherichia coli strain BL21 (DE3) cells, which were grown at $37^{\circ} \mathrm{C}$ to an $\mathrm{A} 600$ of $0.6-0.8$ in LB medium supplemented with antibiotics (kanamycin), prior to the isopropyl $\beta$-D-thiogalactoside induction at a final concentration of $0.5 \mathrm{mM}$. Cultures were allowed to grow at $16^{\circ} \mathrm{C}$ for 20 hours. The cells were then harvested by centrifugation, and the GluA2-LBD was purified using a nickel-nitrolotriacetic acid (Ni-NTA) column (Qiagen, Hilden, Germany) in buffer containing $500 \mathrm{mM}$ imidazole, $50 \mathrm{mM}$ Tris- $\mathrm{HCl}, 150 \mathrm{mM}$ sodium chloride, and $0.5 \mathrm{mM}$ dithiothreitol, at $\mathrm{pH}$ 8.0. For the scintillation proximity assay (SPA) binding assay, the protein was then purified by size exclusion on a Superdex 200 column (GE Healthcare UK, Buckinghamshire, UK) in buffer containing $20 \mathrm{mM}$ HEPES, $50 \mathrm{mM}$ sodium chloride, and $1 \mathrm{mM}$ glutamate, at $\mathrm{pH}$ 7.0. For crystallization trials, GluA2-LBD was purified using a Ni-NTA column, followed by TEV-protease cleavage and additional Ni-affinity chromatography to remove the $6 \times$ His tag of the $\mathrm{N}$ terminus. A final size exclusion step on a Superdex 200 column was employed to remove small amounts of aggregate and residual contaminants. Glutamate $(1 \mathrm{mM})$ was provided as a supplement in all buffers throughout purification. After the last column, the protein was concentrated to $10-15 \mathrm{mg} / \mathrm{ml}$ and stored in buffer containing $20 \mathrm{mM}$ HEPES, $50 \mathrm{mM}$ sodium chloride, and $1 \mathrm{mM}$ glutamate, at $\mathrm{pH}$ 7.0.

pSeqTag2-GluA2-ATD plasmids were transfected to Freestyle 293 cells (Thermo Fisher Scientific) and cultured for 3 days at $37^{\circ} \mathrm{C}$ in FreeStyle 293 Expression Medium (Thermo Fisher Scientific). GluA2o ATD protein secreted into the culture medium was then harvested and purified on a Ni-NTA agarose column (Qiagen) in buffer containing $500 \mathrm{mM}$ imidazole, $50 \mathrm{mM}$ Tris- $\mathrm{HCl}, 150 \mathrm{mM}$ sodium chloride, and $0.5 \mathrm{mM}$ dithiothreitol, at pH 8.0. Subsequent AcTEV (Thermo Fisher Scientific) digestion and size exclusion chromatography with Superdex 200 (GE Healthcare UK) were carried out. After filtration through the last column, the protein was concentrated to $1-2 \mathrm{mg} / \mathrm{ml}$ and stored in buffer containing $20 \mathrm{mM}$ Tris, $150 \mathrm{mM} \mathrm{NaCl}$, and $1 \mathrm{mM}$ dithiothreitol, at $\mathrm{pH}$ 7.5.

Scintillation Proximity Assay. First, $62.5 \mu \mathrm{g}$ YSi $(2-5 \mu \mathrm{m})$ copper his-tag SPA beads (PerkinElmer, Waltham, MA) and $0.25 \mu \mathrm{g}$ His-tagged GluA2o LBD protein (His-LBD) were incubated in $100 \mu \mathrm{l}$ phosphate-buffered saline containing $0.01 \%$ Nonidet P-40 and the indicated amount of glutamate in 96 -well LumiNunc plates (Thermo Fisher Scientific) overnight at $4^{\circ} \mathrm{C}$. Subsequently, test compound and tritium-labeled ligand $\left(40 \mathrm{nM}\left[{ }^{3} \mathrm{H}\right]-\mathrm{HBT} 1\right.$ or $\left.100 \mathrm{nM}\left[{ }^{3} \mathrm{H}\right]-\mathrm{OXP} 1\right)$ were added to each well. For the SPA using His-tagged GluA2o ATD protein (His-ATD), $62.5 \mu \mathrm{g}$ YSi $(2-5 \mu \mathrm{m})$ copper his-tag SPA beads, and $0.25 \mu \mathrm{g}$ His-tagged GluA2o ATD were incubated in $100 \mu$ l phosphatebuffered saline containing the indicated amount of glutamate in 96-well LumiNunc plates for 1 hour at room temperature. Subsequently, $100 \mathrm{nM}\left[{ }^{3} \mathrm{H}\right]-\mathrm{OXP} 1$ was added to each well. Specific binding was defined as total binding minus nonspecific binding, which was estimated in the presence of $0.25 \mu \mathrm{g}$ control protein [His-tagged 
macrophage migration inhibitory factor (MIF) protein] instead of HisLBD or His-ATD. Binding was initiated by addition of a radioligand and continued for $3-5$ hours at room temperature. The radioactivity due to the amount of bound radioligand was measured using a microplate scintillation counter (TopCount NXT; PerkinElmer). All compounds were dissolved in DMSO, and final concentration of solvent was kept to $3 \%$ DMSO for the $\left[{ }^{3} \mathrm{H}\right]$-HBT1/LBD-binding assay. $\mathrm{EC}_{50}$ values were calculated using logistic regression analysis.

Binding Assay Using Rat Hippocampal Membrane. Adult male Sprague-Dawley rats at 6-8 weeks old were sacrificed. Their hippocampi were rapidly dissected, quickly frozen on solid $\mathrm{CO}_{2}$, and stored at $-80^{\circ} \mathrm{C}$ until use. Frozen tissues were homogenized using a Polytron for 30 seconds in 3.4 volumes of ice-cold assay buffer $(30 \mathrm{mM}$ Tris- $\mathrm{HCl}$ at $\mathrm{pH} 7.4$ ). The homogenate was centrifuged at $20,000 \mathrm{~g}$ for 20 minutes $\left(4^{\circ} \mathrm{C}\right)$. The pellet was resuspended for 10 seconds in an equal volume of assay buffer and centrifuged for 20 minutes. The homogenate was washed one more time in an equal volume of assay buffer (for a total of three washes). Membranes were resuspended in 3.4 volumes of assay buffer. The assay mixture consisted of $1.2 \mathrm{mg}$ membrane protein, $90 \mathrm{nM}\left[{ }^{3} \mathrm{H}\right]-\mathrm{HBT} 1$, test compound, $0.025 \%$ Nonidet $\mathrm{P}-40$, and assay buffer to a final volume of $1.0 \mathrm{ml}$. Nonspecific binding was determined with $10 \mu \mathrm{M}$ LY451646. Assays were performed in the presence of $3 \mathrm{mM}$ glutamate, except as indicated. Samples were incubated at $37^{\circ} \mathrm{C}$ for 2 hours and then were filtered through GF/B filters (GE Healthcare UK) presoaked in $0.03 \%$ polyethylenimine. Filters were washed with $20 \mathrm{ml}$ ice-cold assay buffer.

For the binding assay using $\left[{ }^{3} \mathrm{H}\right]$-AMPA, the mixture consisted of $0.3 \mathrm{mg}$ membrane protein, $4 \mathrm{nM}\left[{ }^{3} \mathrm{H}\right]$-AMPA, test compound, $50 \mathrm{mM}$ potassium thiocyanate (KSCN), $0.01 \%$ Nonidet P-40, and assay buffer to a final volume of $1.0 \mathrm{ml}$. Nonspecific binding was determined with $100 \mu \mathrm{M}$ AMPA. Samples were incubated on ice for 1 hour and then filtered through GF/B filters presoaked in $0.03 \%$ polyethylenimine. Filters were washed with $20 \mathrm{ml}$ ice-cold assay buffer.

The radioactivity retained on the filters was measured using a liquid scintillation counter (LSC-6100; ALOKA, Tokyo, Japan). Protein was determined following a bicinchoninic acid assay method (Thermo Fisher Scientific). All compounds were dissolved in DMSO, and the final concentration of solvent was kept to less than $0.3 \%$ DMSO. $\mathrm{EC}_{50}$ values were calculated using logistic regression analysis.

X-Ray Crystallography of the GluA2o LBD/HBT1 Complex and the GluA2o LBD/LY451395 Complex. For crystallization trials, the compounds were added to a final concentration of $1.5 \mathrm{mM}$ and incubated at $16^{\circ} \mathrm{C}$ for a few hours. Crystals were grown at $4^{\circ} \mathrm{C}$ using the vapor diffusion sitting-drop method, with drops containing a 1:1 $(\mathrm{v} / \mathrm{v})$ ratio of protein solution to reservoir solution. The reservoir solution contained 11-18\% polyethylene glycol 3350, 0.1 M sodium acetate, and $0.1 \mathrm{M}$ zinc acetate, at $\mathrm{pH} 4.3-5.4$. Prior to data collection, crystals were immersed in mother liquor solution containing $30 \%$ glycerol and flash frozen in liquid nitrogen. Diffraction data were collected from a single crystal at Advance Light Source Beam Line 5.0.3 using a Quantum210 CCD detector (Area Detector Systems Corp, CA) and placed under a $100 \mathrm{~K}$ nitrogen cryostream. Data sets were reduced and scaled using HKL2000 (Otwinowski and Minor, 1997). Structures were solved by molecular replacement using MOLREP (Vagin and Teplyakov, 2010) from the CCP4 package (Winn et al., 2011) and the coordinates of the GluA2-LBD associated with glutamate (Protein Data Bank code 1FTJ) as a search model. The structures were refined through an iterative procedure utilizing REFMAC (Murshudov et al., 2011), followed by model building in COOT (Emsley et al., 2010). The dictionary files for the ligands were prepared using AFITT (OpenEye Scientific Software, Cambridge, MA). The final models were validated using Molprobity (Chen et al., 2010). Crystallographic processing and refinement statistics are summarized in Supplemental Table 1. All structural figures were generated using PyMOL (Schrödinger, New York, NY).

Statistical Analysis. The statistical significance of the differences between the two groups was assessed using Aspin-Welch's $t$ test or Student's $t$ test. Differences yielding $P$ values $\leq 0.05$ were considered significant. In the experiments that examined the effects of multiple concentrations of test compounds, statistical significance was analyzed using Bartlett's test, which was used for testing the homogeneity of variances, followed by one-tailed Williams' test (for parametric data, $P>0.05$ by Bartlett's test) or one-tailed Shirley-Williams test (for nonparametric data, $P \leq 0.05$ by Bartlett's test) for comparing concentration-dependent effects of multiple concentrations of test compounds with the control group. Differences yielding $P$ values $\leq 0.025$ were considered significant. In the BDNF assay using AMPA, the statistical significance of differences between control and LY451646, LY451395, or OXP1 was assessed using Dunnett's test. Differences yielding $P$ values $\leq 0.05$ were considered significant.

\section{Results}

LY451646 and LY451395 Showed a Bell-Shaped Response for BDNF Protein Production in Primary Neurons. LY451646 (Fig. 1A) is reported to elicit a bellshaped response for BDNF mRNA expression in rat hippocampus (Mackowiak et al., 2002). We examined the effect of LY451646 on BDNF production in primary neurons. AMPA concentration-dependently increased BDNF protein levels in primary neurons (Supplemental Fig. 1). Under the conditions, in agreement with the previous in vivo study, LY451646 triggered a bell-shaped response for BDNF protein production in primary neurons in the presence of low concentration of AMPA ( $1 \mu \mathrm{M}$ corresponds to about $10 \%$ of maximal effective concentration of AMPA); the maximum effect of LY451646 on BNDF production was observed at $0.3 \mu \mathrm{M}$, but its effect was attenuated at higher concentrations (Fig. 1B). LY451395 (Fig. 1A), an AMPA-R potentiator with chemical structure similar to that of LY451646, also showed a bell-shaped response in the BDNF assay; the maximum effect of LY451395 on BNDF production was observed at $0.1 \mu \mathrm{M}$, but its effect was attenuated at higher concentrations (Fig. 1B). Interestingly, LY451646 and LY451395 showed agonistic effects and concentration-dependently increased BDNF protein levels at $0.3-3$ and $0.1-1 \mu \mathrm{M}$, respectively, even in the absence of AMPA (Fig. 1B). Note that both LY451646 and LY451395 started to show bell-shaped response in which they started to exhibit the agonistic effects. LY451646 at up to $1 \mu \mathrm{M}$ showed little cytotoxicity in the presence and absence of AMPA; LY451646 at $3 \mu \mathrm{M}$ showed a weak cytotoxicity in the presence of AMPA, but not in the absence of AMPA (Fig. 1C). LY451395 showed little cytotoxicity in the presence and absence of AMPA (Fig. 1C). These results suggest that the cytotoxicity does not affect the bell-shaped response. Because LY451646 and LY451395 had similar properties in the BDNF assay, we used LY451395 for further in vitro characterization.

LY451395 Had Agonistic Effects in Primary Neurons in Patch-Clamp and $\mathrm{Ca}^{2+}$ Influx Assays. Because primary neurons were stimulated with LY451646 or LY451395 for a long period (24 hours) to measure BDNF protein production in primary neurons, the observed agonist-like effects (BDNF production in the absence of AMPA) may not be related to their intrinsic agonistic effects (Fig. 1B). For example, glutamate may be released from primary neurons during 24-hour culture. Thus, we conducted a patch-clamp study to examine whether LY451395 has an intrinsic agonistic effect. LY451395 induced AMPA-R-mediated current both in the presence and absence of agonist (AMPA) in primary neurons (Fig. 2A). Thus, we hypothesized that the agonistic property is related to the bell-shaped response and endeavored 
A

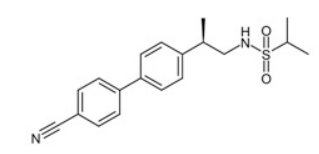

LY451395

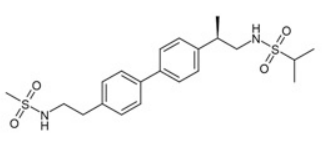

B

LY451646

(+)

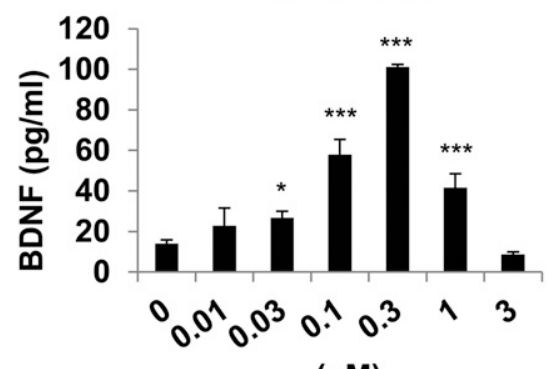

( $\mu \mathrm{M})$

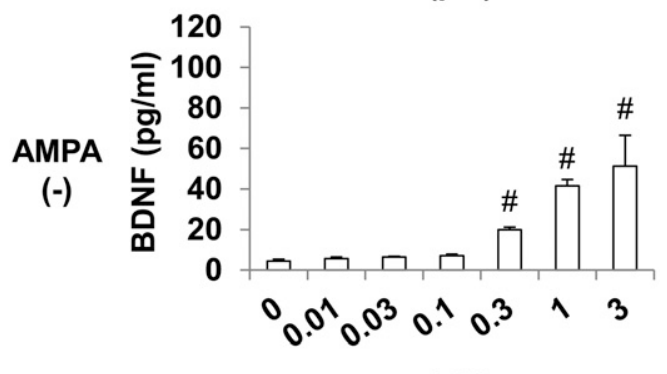

( $\mu \mathrm{M})$

C

LY451646

AMPA
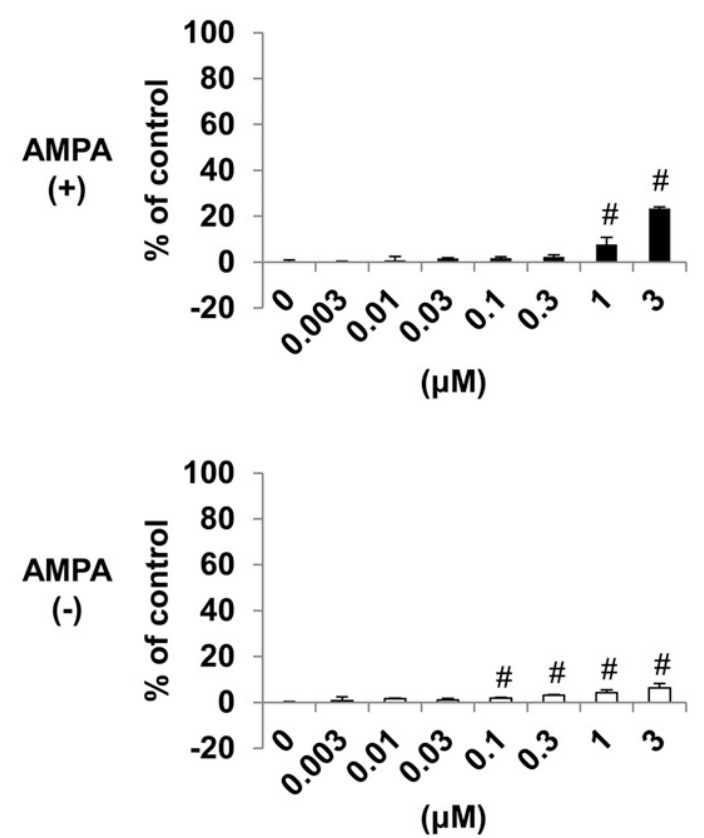

LY451395

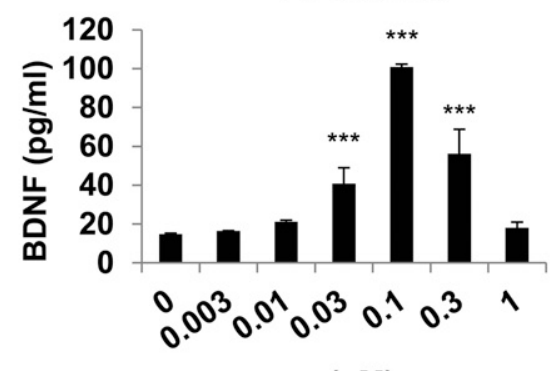

$(\mu \mathrm{M})$

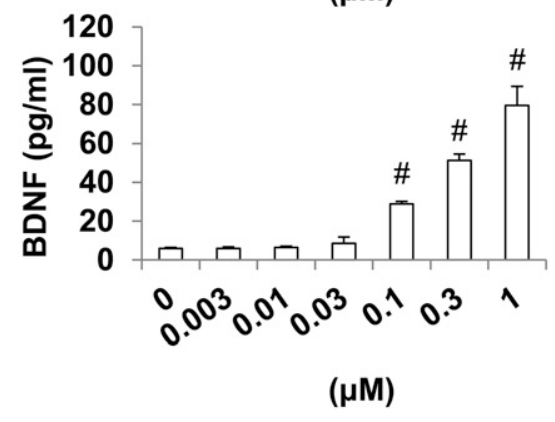

LY451395
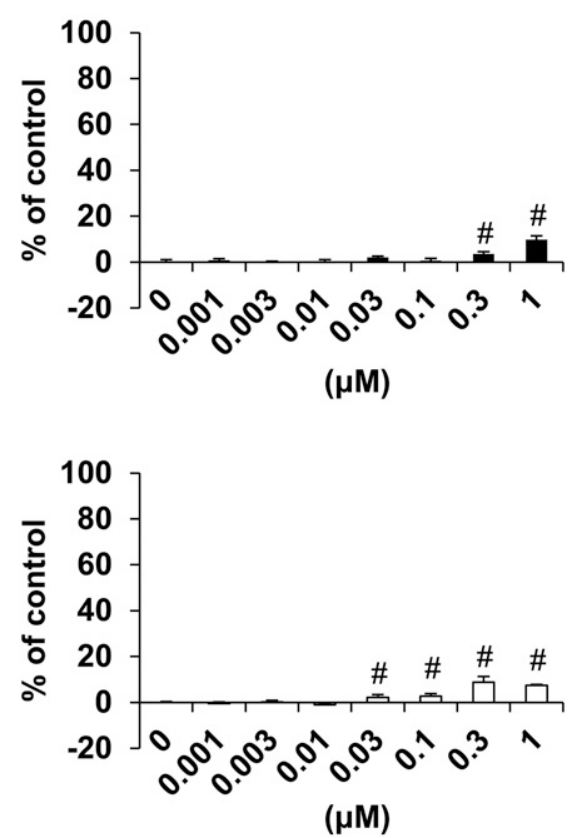

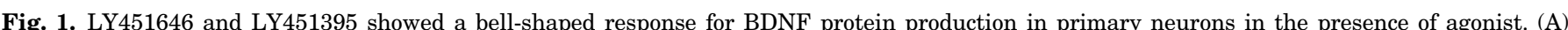

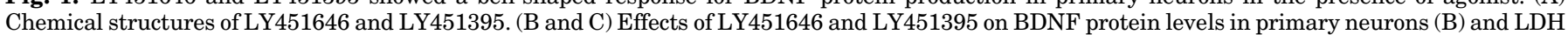

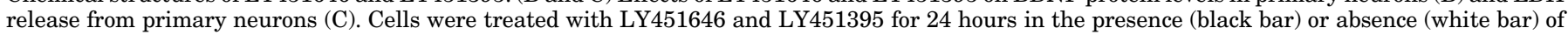

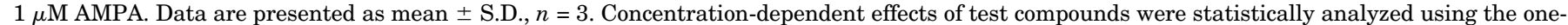

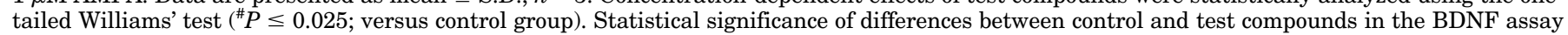
using AMPA was determined using Dunnett's test ( $* P \leq 0.05 ; * * * P \leq 0.001)$. 
to discover novel AMPA-R potentiators with lower agonistic effects. However, the patch-clamp study and the BDNF assay are not suitable for a screening assay, because they are laborintensive and low throughput. Thus, we further evaluated LY451395 by $\mathrm{Ca}^{2+}$ influx assays using a cell line expressing AMPA-Rs or primary neurons. To our surprise, LY451395 induced $\mathrm{Ca}^{2+}$ influx both in the presence and absence of AMPA in primary neurons (Fig. 2B), whereas LY451395 induced $\mathrm{Ca}^{2+}$ influx only in the presence of glutamate in GluA1i and TARP $\gamma 2$-expressing $\mathrm{CHO}$ cells (GluA1i CHO cells) (Fig. 2C); $\mathrm{EC}_{50}$ in the presence and absence of AMPA in primary neurons was 0.11 and $0.88 \mu \mathrm{M}$, respectively, and $\mathrm{EC}_{50}$ in GluA1i CHO cells was $0.37 \mu \mathrm{M}$. Thus, the widely used $\mathrm{Ca}^{2+}$ influx assays with cell lines expressing AMPA-Rs for drug screening may not be suitable to discover AMPA-R potentiators with lower agonistic effects.
We next examined whether LY451395 binds to the glutamate-binding site on AMPA-R to produce its agonistic effect. In a binding assay measuring the competitive inhibition of $\left[{ }^{3} \mathrm{H}\right]$-AMPA binding to rat hippocampal membranes, LY451395 did not inhibit $\left[{ }^{3} \mathrm{H}\right]$-AMPA binding to rat hippocampal membranes, whereas a competitive AMPA-R antagonist, NBQX, did (Fig. 2D). Thus, LY451395 may allosterically activate AMPA-Rs in the absence of agonist in primary neurons.

HBT1 Activated AMPA-R in an Agonist-Dependent Manner and Increased BDNF Protein Levels at a Broader Range of Concentrations in Primary Neurons Compared with LY451395 and OXP1. To discover novel AMPA-R potentiators with lower agonistic effect in primary neurons, we initially screened the chemical library by a $\mathrm{Ca}^{2+}$ influx assay using GluA1i CHO cells, and then characterized
A

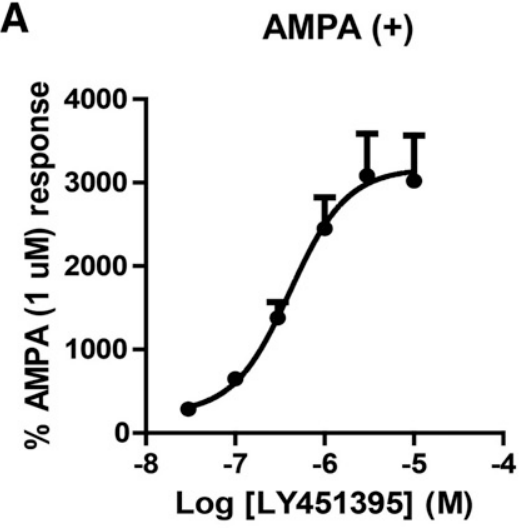

B

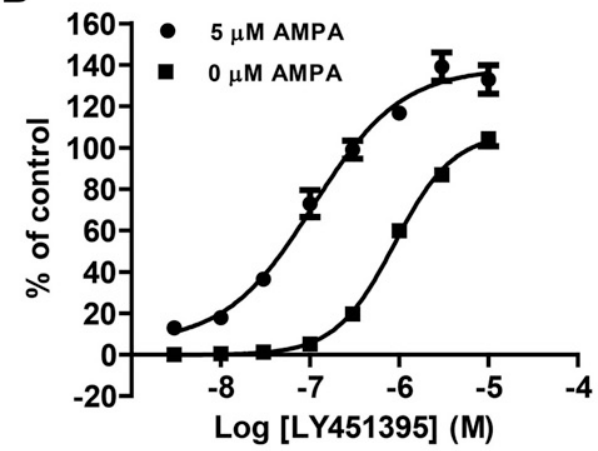

D

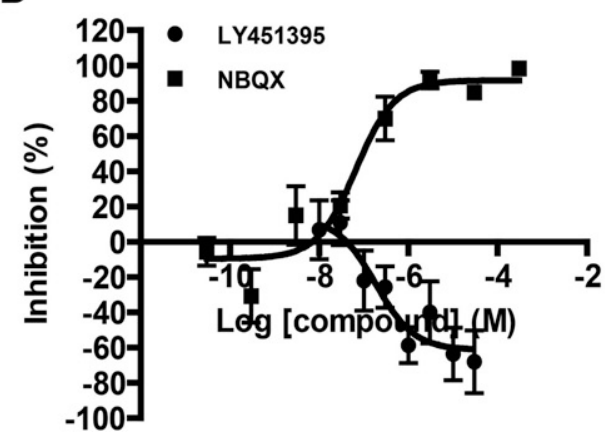

Fig. 2. LY451395 showed agonistic effects in primary neurons, but not in GluA1i CHO cells. (A) Effects of LY451395 on AMPA receptor-mediated currents in the presence or absence of $1 \mu \mathrm{M}$ AMPA in a patch-clamp study using primary neurons. Data are presented as the mean \pm S.E.M. $(n=4-9)$, (B) Effects of LY451395 on $\mathrm{Ca}^{2+}$ influx in primary neurons in the presence or absence of $5 \mu \mathrm{M}$ AMPA. (C) Effects of LY451395 on $\mathrm{Ca}^{2+}$ influx in GluA1i CHO cells in the presence or absence of $3 \mathrm{mM}$ glutamate. (D) Effects of LY451395 and NBQX on the binding of $\left[{ }^{3} \mathrm{H}\right]$-AMPA to rat hippocampal membranes. Data are presented as mean \pm S.D., $n=3-4$. 
the agonistic effect of hit compounds for AMPA-R by a $\mathrm{Ca}^{2+}$ influx assay using primary neurons. As a result, we discovered two unique AMPA-R potentiators: HBT1 and OXP1 (Fig. 3A). Both HBT1 and OXP1 induced $\mathrm{Ca}^{2+}$ influx in a glutamatedependent manner in GluA1i CHO cells, with an $\mathrm{EC}_{50}$ of 4.6 and $2.5 \mu \mathrm{M}$, respectively (Fig. 3, B and C), and their glutamate-dependent $\mathrm{Ca}^{2+}$ influx was suppressed by NBQX (Fig. 3D). Both HBT1 and OXP1 induced $\mathrm{Ca}^{2+}$ influx in an AMPA-dependent manner in primary neurons, with an $\mathrm{EC}_{50}$ of 1.3 and $4.3 \mu \mathrm{M}$, respectively (Fig. 3, E and F), and their AMPA-dependent $\mathrm{Ca}^{2+}$ influx was suppressed by NBQX (Fig. 3G). Interestingly, HBT1 induced AMPA-R-mediated current only in the presence of AMPA in a patch-clamp study using primary neurons, whereas OXP1 induced AMPA$\mathrm{R}$-mediated current both in the presence and absence of AMPA (Fig. $3 \mathrm{H}$ ). In a binding assay measuring the competitive inhibition of $\left[{ }^{3} \mathrm{H}\right]$-AMPA binding to rat hippocampal membranes, neither HBT1 nor OXP1 inhibited $\left[{ }^{3} \mathrm{H}\right]-\mathrm{AMPA}$ binding to rat hippocampal membranes (Supplemental Fig. 2). These results suggest that OXP1 allosterically activates AMPA-Rs in the absence of agonist in primary neurons. Next, we examined the effects of HBT1 and OXP1 on BDNF protein production in primary neurons. HBT1 concentrationdependently increased BDNF protein levels in the presence of AMPA, and the maximum effect of HBT1 was maintained at 1-10 $\mu \mathrm{M}$. HBT1 at up to $3 \mu \mathrm{M}$ showed no increase of BDNF protein levels in the absence of AMPA (Fig. 3I). OXP1 prompted a bell-shaped response in the presence of AMPA; the maximum effect of OXP1 on BNDF production was observed at $1 \mu \mathrm{M}$, but its effect was attenuated at higher concentrations (Fig. 3I). OXP1 at $\geq 1 \mu \mathrm{M}$ increased BDNF protein levels in the absence of AMPA (Fig. 3I). Similar to LY451646 and LY451395, OXP1 started to exhibit the bellshaped response, in which it started to show agonistic effect in BDNF production in primary neurons.

HBT1 showed no cytotoxicity in the presence or absence of AMPA, whereas OXP1 showed a weak but significant cytotoxicity in the presence and absence of AMPA at 1-10 and 0.1-10 $\mu \mathrm{M}$, respectively (Fig. 3J). Taken together, these results suggest that the lower agonistic effect of HBT1 in the induction of both $\mathrm{Ca}^{2+}$ influx and AMPA-R-mediated current may be associated with its lower risks of bell-shaped response in BDNF production in primary neurons compared with LY451395 and OXP1.

Each subunit of AMPA-R has different function, and subunit selectivity of AMPA-R potentiators may affect their functional outcomes (Ward et al., 2010). Thus, we examined the subunit selectivity of HBT1 and OXP1 by $\mathrm{Ca}^{2+}$ influx assay using CHO cells expressing GluA1-4i and TARPs $\gamma 2$ or expressing GluA1-4o and TARPs $\gamma 2$. As shown in Supplemental Table 2, HBT1 and OXP1 showed little subunit selectivity. We also confirmed that these compounds did not activate kainate receptors at concentrations up to $100 \mu \mathrm{M}$ (Supplemental Table 2).

To gain insight into the difference between these compounds, we investigated concentrations of glutamate required for AMPA-R activation by HBT1 and OXP1 in GluA1i CHO cells. Interestingly, HBT1 required higher concentration of glutamate than OXP1 to activate AMPA-Rs; the $\mathrm{EC}_{50}$ of the glutamate concentration required to activate AMPA-R by HBT1 and OXP1 was 2.5 and $0.25 \mu \mathrm{M}$, respectively (Fig. $3 \mathrm{~K})$, suggesting a difference in modes of AMPA-R activation between HBT1 and OXP1.
HBT1 and LY451395 Bound to a Pocket in the LBD of AMPA-R with a Different Binding Mode. We examined the binding properties of HBT1 and OXP1 to AMPA-R. A hydrophilic pocket at the dimer interface of the LBD of AMPA-R is known as a binding pocket for several AMPA-R potentiators (Kaae et al., 2007; Sobolevsky et al., 2009). We investigated the interaction between HBT1 and LBD using a SPA measuring the binding of radiolabeled $\left[{ }^{3} \mathrm{H}\right]-\mathrm{HBT} 1$ to a His-tagged GluA2o LBD protein (His-LBD). Specific interaction between His-LBD and $\left[{ }^{3} \mathrm{H}\right]-\mathrm{HBT} 1$ was detected in the presence of $100 \mu \mathrm{M}$ glutamate; however, when another Histagged protein such as MIF (His-MIF) was used instead of HisLBD, binding of $\left[{ }^{3} \mathrm{H}\right]-\mathrm{HBT} 1$ was not detected. Thus, HBT1 may specifically interact with Glu2o LBD (Fig. 4A). We also examined the interaction between OXP1 and LBD using a SPA with $\left[{ }^{3} \mathrm{H}\right]-\mathrm{OXP} 1$ and His-LBD. Specific interaction between His-LBD and $\left[{ }^{3} \mathrm{H}\right]-\mathrm{OXP} 1$ was not detected under our experimental conditions (Fig. 4B).

We next examined the effects of glutamate on the binding of $\left[{ }^{3} \mathrm{H}\right]-\mathrm{HBT} 1$ to His-LBD. Glutamate increased binding of $\left[{ }^{3} \mathrm{H}\right]-$ HBT1 to His-LBD in a concentration-dependent manner (Fig. 4C). Thus, HBT1 would bind to LBD on AMPA-R in a glutamate-dependent manner. The binding affinity of $\left[{ }^{3} \mathrm{H}\right]$ HBT1 to His-LBD was measured in the presence of $100 \mu \mathrm{M}$ glutamate. Analysis of the saturation isotherms gave a single saturable affinity binding site $(\mathrm{Kd}=543 \mathrm{nM})$ (Fig. 4D). In the SPA measuring the competitive inhibition of $\left[{ }^{3} \mathrm{H}\right]-\mathrm{HBT} 1$ binding to His-LBD, HBT1 and LY451395 exhibited $\mathrm{IC}_{50}$ of 0.64 and $0.03 \mu \mathrm{M}$, respectively (Fig. 4E).

The binding property of $\left[{ }^{3} \mathrm{H}\right]-\mathrm{HBT} 1$ to native AMPA-R was also assessed using rat hippocampal membranes. Glutamate increased the binding of $\left[{ }^{3} \mathrm{H}\right]$-HBT1 to rat hippocampal membranes in a concentration-dependent manner, and this $\left[{ }^{3} \mathrm{H}\right]-\mathrm{HBT} 1$ binding to rat hippocampal membranes was not observed in the absence of glutamate (Fig. 4F). Analysis of the saturation isotherms indicated a single saturable affinity binding site ( $\mathrm{Kd}=416 \mathrm{nM}$ ) (Fig. 4G). In the binding assay measuring the competitive inhibition of $\left[{ }^{3} \mathrm{H}\right]-\mathrm{HBT} 1$ binding to rat hippocampal membranes, HBT1 and LY451395 exhibited an $\mathrm{IC}_{50}$ of 0.28 and $0.02 \mu \mathrm{M}$, respectively (Fig. $4 \mathrm{H}$ ).

To understand the structural basis for the interaction between HBT1 and LBD, we determined the crystal structures of the GluA2o LBD/glutamate/HBT1 complex and the GluA2o LBD/glutamate/LY451395 complex. Data collection and refinement statistics are shown in Supplemental Table 1. Both HBT1 and LY451395 bound to the cleft formed by the dimer interface between the two protomers with a compoundto-protomer stoichiometry of 1:2 to stabilize the dimer interface in the active conformation (Fig. 4I). In the crystallographic refinement, the dimer interface was occupied by two ligand molecules, which are related by a noncrystallographic twofold axis, each with an occupancy of 0.5. Electron density maps of HBT1 and LY451395 are shown in Supplemental Fig. 3.

We next examined the interaction of HBT1 and LY451395 with amino acid residues in the LBD, using GluA2o LBD. For HBT1, the trifluoromethylpyrazole moiety and tetrahydrobonzohiophene ring occupied two hydrophobic pockets of the dimer interface, whereas two sulfonamide moieties of LY451395 occupied the same sites (Fig. 4J). The hydrophobic pockets were composed of K514, P515, V771, and L772 in one protomer of the dimer, and I502 and K751 in another protomer. The sulfonamide groups of LY451395 formed 
A

HBT1

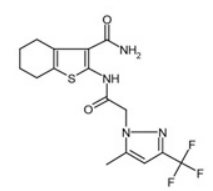

OXP1

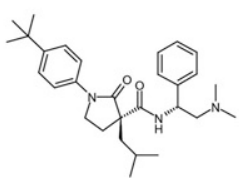

B

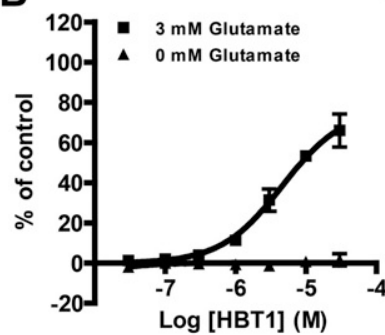

E

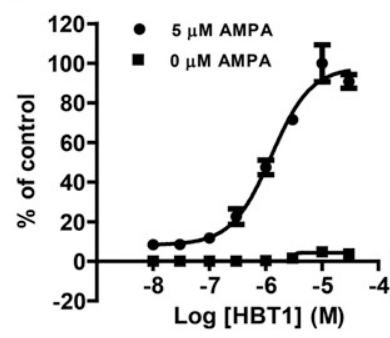

H
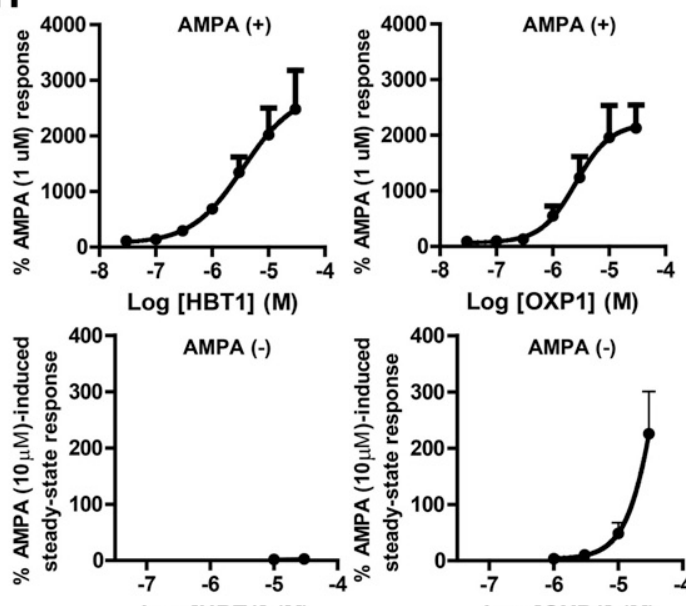

Log [HBT1] (M)

\section{J}
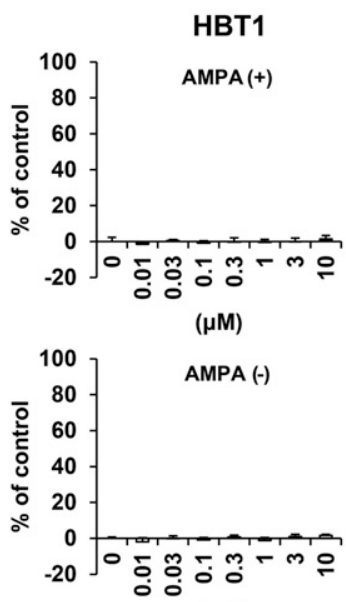

$(\mu \mathrm{M})$

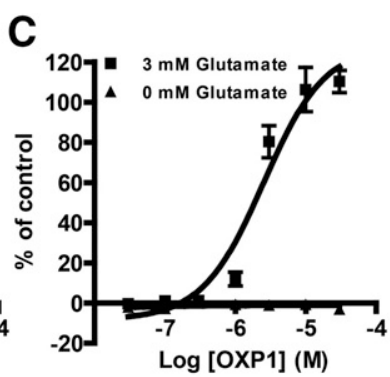

F

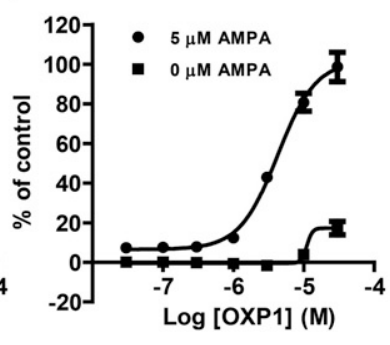

I

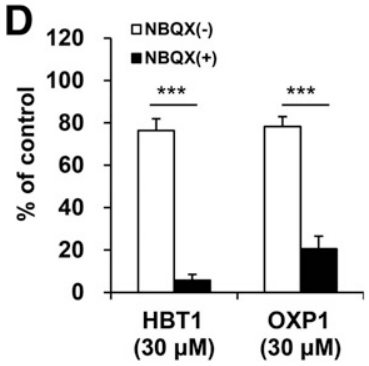

G

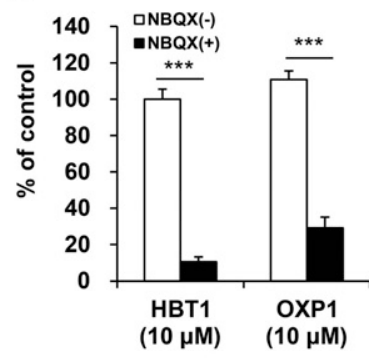

OXP1

AMPA (+)
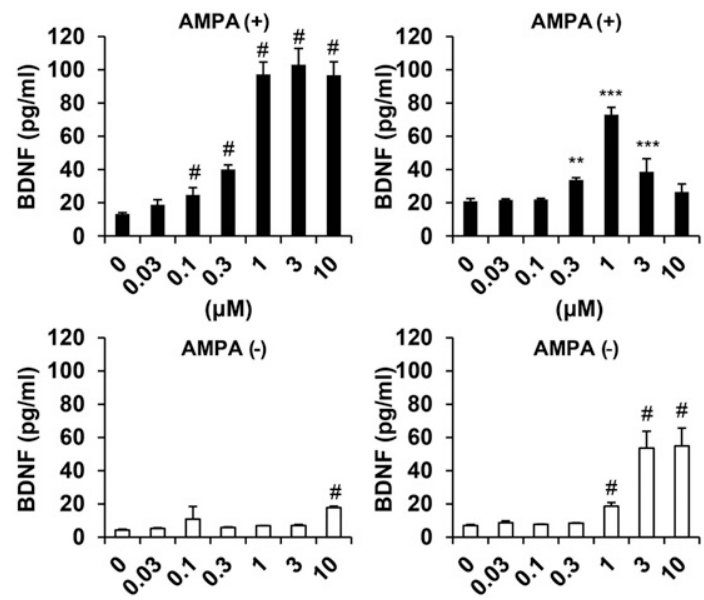

$(\mu \mathrm{M})$

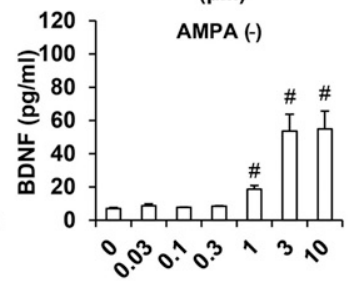

$(\mu \mathrm{M})$

Fig. 3. HBT1 activated AMPA-R in an agonist-dependent manner and increased BDNF protein levels at a broader range of concentrations in primary neurons compared with LY451395 and OXP1. (A) Chemical structure of HBT1 and OXP1. (B and C) Effects of HBT1 (B) and OXP1 (C) on Ca ${ }^{2+}$ influx in GluAi CHO cells in the presence or absence of $3 \mathrm{mM}$ glutamate. (D) Effects of $100 \mu \mathrm{M}$ NBQX on the induction of $\mathrm{Ca}^{2+}$ influx by HBT1 or OXP1 in the presence of $10 \mu \mathrm{M}$ glutamate. (E and F) Effects of HBT1 (E) and OXP1 (F) on $\mathrm{Ca}^{2+}$ influx in primary neurons in the presence or absence of $5 \mu \mathrm{M}$ AMPA. (G) Effects of $10 \mu \mathrm{M}$ NBQX on the induction of $\mathrm{Ca}^{2+}$ influx by $10 \mu \mathrm{M}$ HBT1 or $10 \mu \mathrm{M}$ OXP1 in the presence of $5 \mu \mathrm{M}$ AMPA. (H) Effects of HBT1 and OXP1 on AMPA receptor-mediated currents in the presence or absence of $1 \mu \mathrm{M}$ AMPA in a patch-clamp study using primary neurons. Data are presented as the mean \pm S.E.M. $(n=4-9)$. (I and J) Effects of HBT1 and OXP1 on BDNF protein levels in primary neurons (I) and LDH release from primary neurons (J). Cells were treated with HBT1 or OXP1 for 24 hours in the presence (black bar) or absence (white bar) of AMPA $(1 \mu \mathrm{M})$. Data are presented as mean \pm S.D., 
hydrogen bonds with main-chain atoms of P515 and G752 in both pockets (Fig. 4J). HBT1 formed two hydrogen bonds with the side chain of S518 (Fig. 4J). The side chain of S518 exhibited two alternative conformations in the structure with HBT1, whereas S518 was found in one conformation away from the compound to prevent steric clashes in the structure with LY451395. Although LY451395 had no direct hydrogen bond with S518 or S750, the biphenyl moiety made van der Waals contacts with P515 (Fig. 4J). HBT1 and LY451395 bind to essentially the same site in the dimer interface with a distinct binding mode. The sulfonamide groups of LY451395 made not only hydrophobic interactions, but also hydrogen bonds with P515 and G752, whereas HBT1 occupied hydrophobic pockets without polar interactions. This difference may be attributed to the lower binding potency of HBT1 compared with LY451395.

OXP1, via Binding to a Different Site from That of HBT1, Promoted Binding between HBT1 and AMPA-R and Activated AMPA-R in the Absence of Agonist. We assessed whether OXP1 affects the binding of $\left[{ }^{3} \mathrm{H}\right]-\mathrm{HBT} 1$ to the LBD by the two competitive binding assays. Both in the SPA using His-LBD and in the binding assay using hippocampal membranes, OXP1 failed to inhibit binding of $\left[{ }^{3} \mathrm{H}\right]$ HBT1 to His-LBD or hippocampal membranes (Fig. 5, A and B). These data were in line with the data showing the lack of binding between $\left[{ }^{3} \mathrm{H}\right]-\mathrm{OXP} 1$ and LBD (Fig. 4B). Considering that HBT1 and OXP1 had similar potency in the $\mathrm{Ca}^{2+}$ influx assays (Fig. 3, E and F; Supplemental Table 2), the binding site of OXP1 on AMPA-R would differ from that of HBT1.

The AMPA-R ATD may possess an allosteric modulator site for small molecules, although an AMPA-R ATD ligand has not been reported yet (Sukumaran et al., 2011). We investigated the interaction between OXP1 and ATD by a SPA using $\left[{ }^{3} \mathrm{H}\right]$ OXP1 and a His-tagged GluA2o ATD protein (His-ATD). Weak but specific-like interactions between His-ATD and $\left[{ }^{3} \mathrm{H}\right]$ OXP1 were detected in the presence of $100 \mu \mathrm{M}$ glutamate (Fig. 5C). When His-MIF was used instead of His-ATD, no binding of $\left[{ }^{3} \mathrm{H}\right]-\mathrm{OXP} 1$ was detected (Fig. $5 \mathrm{C}$ ). We examined the effects of glutamate on the binding of $\left[{ }^{3} \mathrm{H}\right]$-OXP1 to His-ATD. Glutamate did not affect $\left[{ }^{3} \mathrm{H}\right]-\mathrm{OXP} 1$ binding to His-ATD (Fig. 5D). To further investigate whether OXP1 activates AMPA-R through the interaction with ATD, we introduced various point mutations in the ATD of GluA2o by an alanine-scanning mutagenesis, and then mutant GluA2os were expressed in human embryonic kidney 293T cells. Evaluation of OXP1induced $\mathrm{Ca}^{2+}$ influx using HBT1 as a control LBD binder revealed that no GluA2o mutations selectively reduced the activity of OXP1; GluA2o mutations that reduced the activity of OXP1 also reduced the activity of HBT1 (Supplemental Table 3). More than 30 GluA2o mutations in the ATD resulted in the reduction of the activity of HBT1 $(<20 \%)$, and these amino acids may be critical to maintaining AMPA-R activity. Although we could not find the presumed OXP1 binding site in the ATD in this mutation study, there is still a possibility that OXP1 activates AMPA-R through the interaction with those amino acid residues of the ATD.
AMPA-R potentiators discovered using a functional assay may have binding affinities to multiple sites on AMPA-R, such as HBT1 binding site (HBT1 site) and OXP1 binding site (OXP1 site). Thus, we examined the effects of HBT1 site and OXP1 site costimulation on AMPA-R activation. As shown in Fig. 3, E and F, HBT1 and OXP1 did not induce $\mathrm{Ca}^{2+}$ influx in the absence of AMPA in primary neurons at concentrations up to 30 and $10 \mu \mathrm{M}$, respectively. Interestingly, coapplication of $30 \mu \mathrm{M}$ HBT1 with 3 or $10 \mu \mathrm{M}$ OXP1 induced $\mathrm{Ca}^{2+}$ influx in the absence of AMPA in primary neurons (Fig. 5E), and that was not observed in GluA1i CHO cells (Fig. 5F). The $\mathrm{Ca}^{2+}$ influx induced by the coapplication of HBT1 with OXP1 $(10 \mu \mathrm{M})$ was inhibited by NBQX (Fig. 5G). Costimulation with HBT1 and OXP1 may activate AMPA-R in the absence of agonist in primary neurons. OXP1, but not HBT1, did bind to AMPA-R in the absence of glutamate (Fig. 4F; Fig. 5D). Thus, we assessed whether OXP1 can enhance binding of HBT1 to AMPA using $\left[{ }^{3} \mathrm{H}\right]$-HBT1 and hippocampal membranes in the absence of glutamate or in the presence of a low concentration of glutamate $(30 \mu \mathrm{M})$; we considered the possibility that costimulation with HBT1 and OXP1 can make AMPA-R hypersensitive to a very low concentration of endogenous glutamate released from primary neurons. OXP1 concentration-dependently increased the binding of $\left[{ }^{3} \mathrm{H}\right]-\mathrm{HBT} 1$ to rat hippocampal membranes under both conditions (Fig. 5H). Accordingly, OXP1 may enhance binding of HBT1 to AMPA-R in the absence of agonist and in the presence of a low concentration of agonist.

\section{Discussion}

AMPA-R potentiators such as LY451646 and LY451395 have risks of narrow bell-shaped responses in various pharmacological effects, including in vivo BDNF induction (Mackowiak et al., 2002; Bai et al., 2003; Fowler et al., 2004; Jhee et al., 2006; Bernard et al., 2010). We found that LY451646 and LY451395 showed a bell-shaped response for BDNF protein production in primary neurons. Thus, the in vitro BDNF assay would be useful for the evaluation of risks of the bell-shaped response of AMPA-R potentiators, although further studies to investigate the relationship of those risks between the in vitro BDNF assay and in vivo pharmacological assays are needed.

LY451395 activated AMPA-Rs in the absence of an agonist in primary neurons in both the patch-clamp study and the $\mathrm{Ca}^{2+}$ influx assay, whereas it induced $\mathrm{Ca}^{2+}$ influx in a glutamate-dependent manner in a widely used GluA1iexpressing cell line. Thus, LY451395 seems to have agonistic effect against physiologic AMPA-Rs. In line with this observation, LY404187, a racemic mixture that includes LY451646, was reported to induce large currents at concentrations higher than $1 \mu \mathrm{M}$ during the recording (in the absence of agonist) in a patch-clamp study using primary neurons (Gates et al., 2001), whereas LY451646 was reported to show no intrinsic activity in cell lines expressing AMPA-Rs (Miu et al., 2001). The very

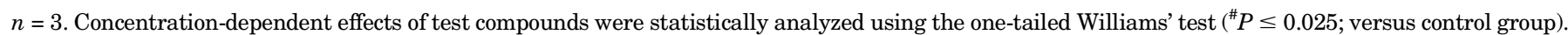

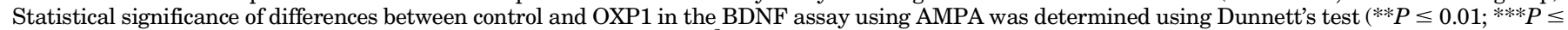

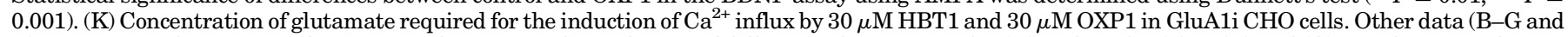

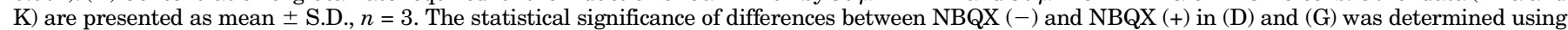
Aspin-Welch's $t$ test or Student's $t$ test ( $* * * P \leq 0.001)$. 
A

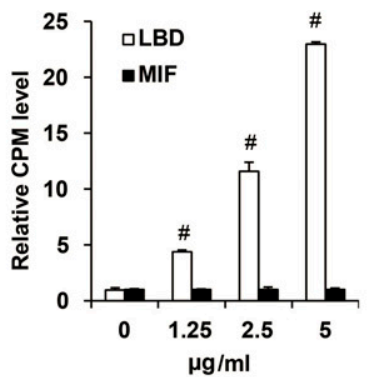

C

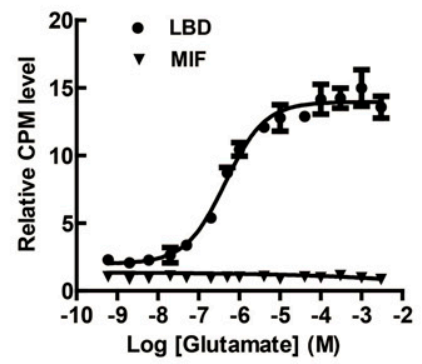

E

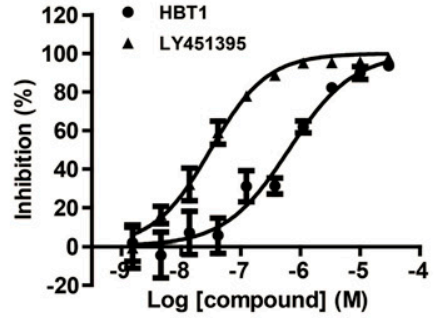

G

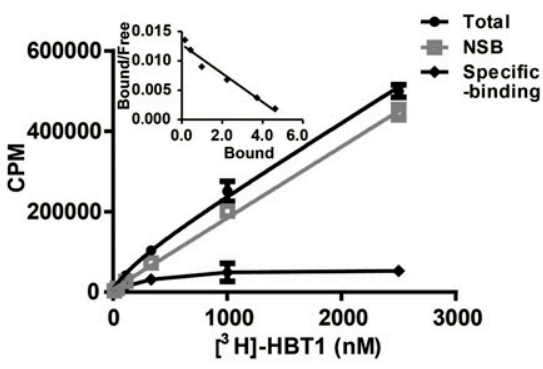

I

HBT1

LY451395

Protomer A

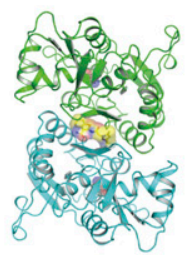

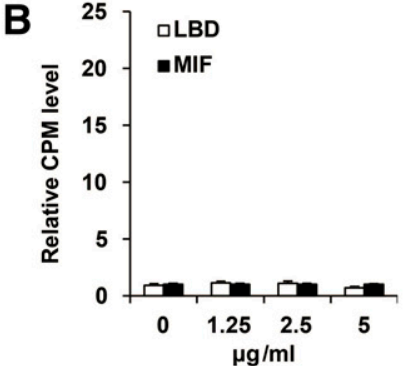

D

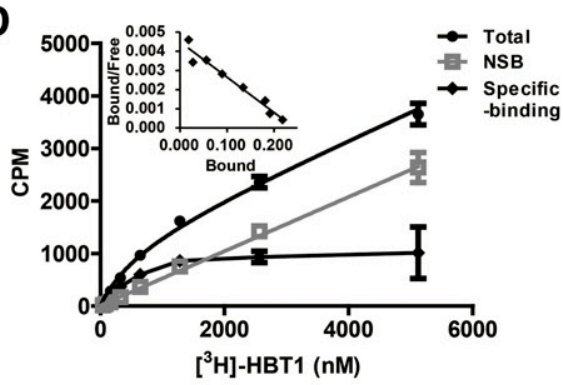

$\mathbf{F}$

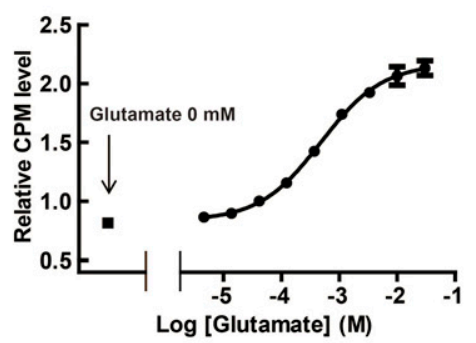

H

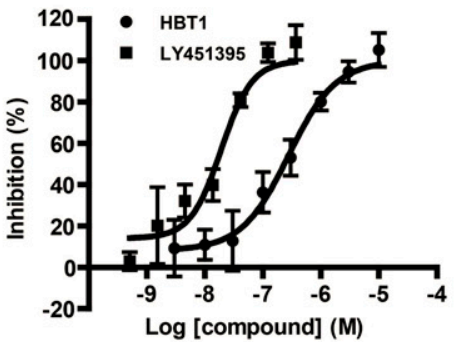

J

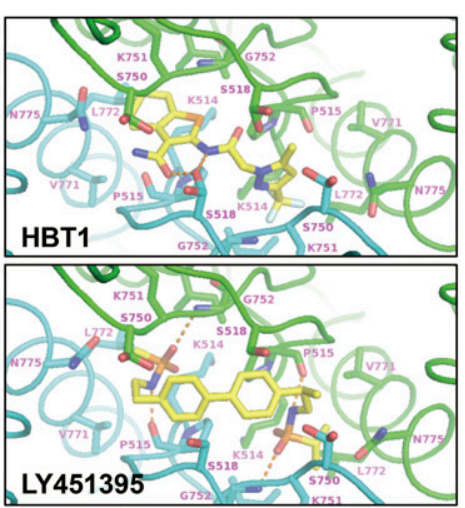

Fig. 4. HBT1 and LY451395 bound to a pocket in the LBD of AMPA-R using a different binding mode. (A) SPA measurement of selective $\left[{ }^{3} \mathrm{H}\right]$-HBT1 binding to His-tagged GluA2o LBD (His-LBD). The 6His-tagged human MIF (His-MIF) was used as a control protein. (B) SPA measurement of selective $\left[{ }^{3} \mathrm{H}\right]-\mathrm{OXP} 1$ binding to His-LBD. (C) Effects of glutamate on the binding of $\left[{ }^{3} \mathrm{H}\right]-\mathrm{HBT} 1$ to His-LBD. (D) Analysis of saturation isotherms with $\left[{ }^{3} \mathrm{H}\right]-\mathrm{HBT} 1$ indicating a single saturable binding site in His-LBD. (E) Displacement studies with HBT1 and LY451395 using SPA with $\left[{ }^{3} \mathrm{H}\right]-\mathrm{HBT} 1$ and His-LBD. (F) Effects of glutamate on the binding of $\left[{ }^{3} \mathrm{H}\right]-\mathrm{HBT} 1$ to hippocampal membranes. (G) Analysis of saturation isotherms with $\left[{ }^{3} \mathrm{H}\right]$-HBT1 disclosing a single saturable binding site in rat hippocampal membranes. (H) Displacement studies with HBT1 and LY451395 using the binding assay with $\left[{ }^{3} \mathrm{H}\right]-\mathrm{HBT} 1$ and rat hippocampal membranes. (I) Overall structure of GluA2o LBD in complex with HBT1 and LY451395. HBT1 and LY451395 are shown in yellow, glutamate is shown in gray, and the two protomers comprising the dimer are shown in green (protomer A) and cyan (protomer B). Both compounds bind at the dimer interface in two symmetrical orientations. It is noted that only one of the conformations is described, for clarity. (J) Close-up view of the binding site of HBT1 (upper) and LY451395 (lower). The compounds are shown in yellow. The protomers A and B are shown in green and cyan, respectively. The side chains of S518 and S750 exhibit alternative conformations. Hydrogen bonds are shown as orange dashed lines. Data are presented as mean \pm S.D., $n=3-4$. Concentration-dependent effects of His-LBD in (A) and (B) were statistically analyzed using the one-tailed Williams' test ( ${ }^{\#} P \leq 0.025$; versus control group). low concentration of endogenous glutamate released from primary neurons would be related to this agonist-like effect of LY451395. Even so, LY451395 would be hypersensitive to glutamate and behave almost as an agonist in the brain. LY451395 showed the agonistic effects in the patch-clamp study, the $\mathrm{Ca}^{2+}$ influx assay, and the BDNF assay, from a concentration of about $0.3 \mu \mathrm{M}$, at which it started to show a bell-shaped response in the presence of low concentration of AMPA in the BDNF assay. Thus, we hypothesized that the agonistic effect was related to the bell-shaped response of 


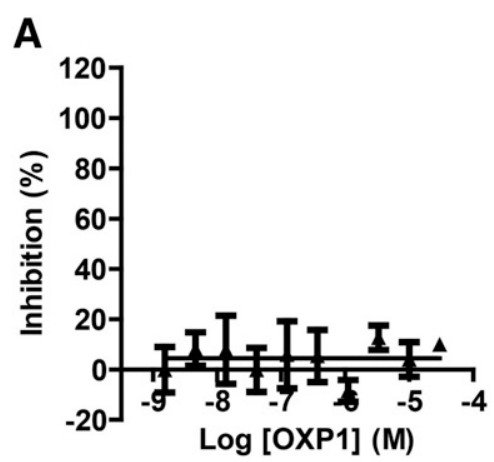

D

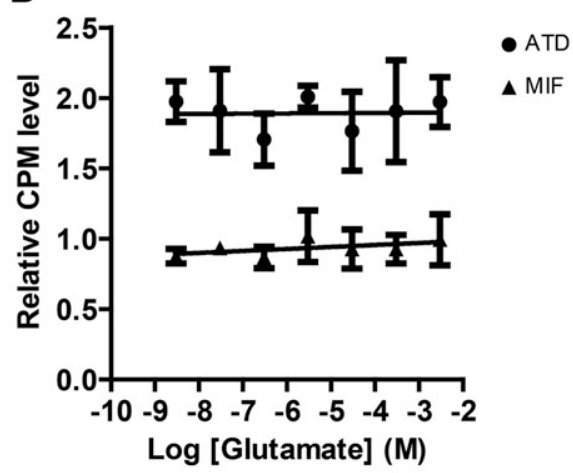

G

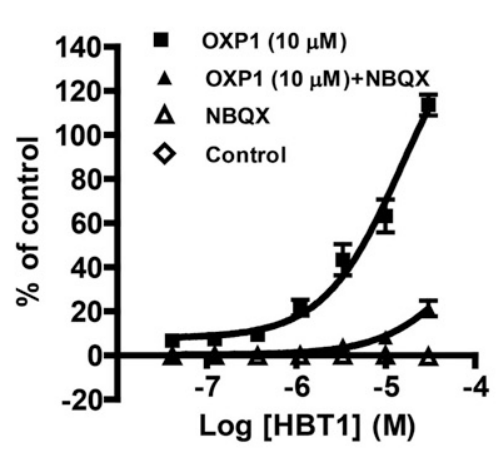

B

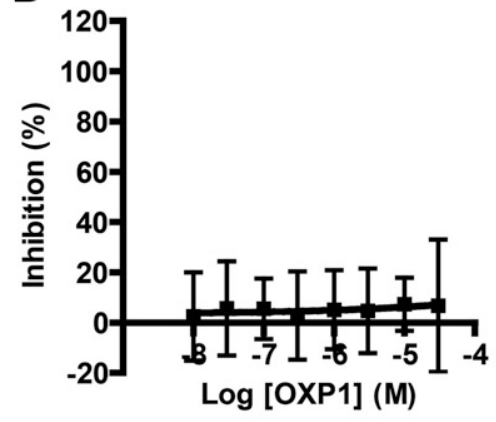

E

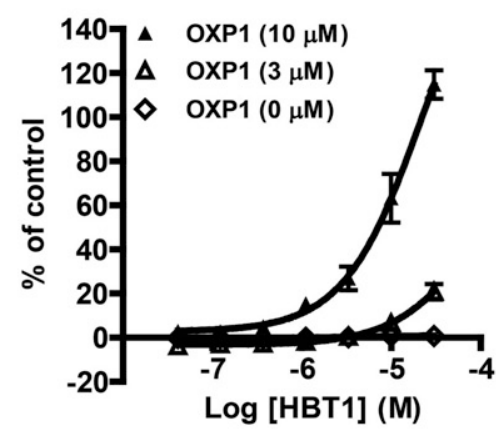

H

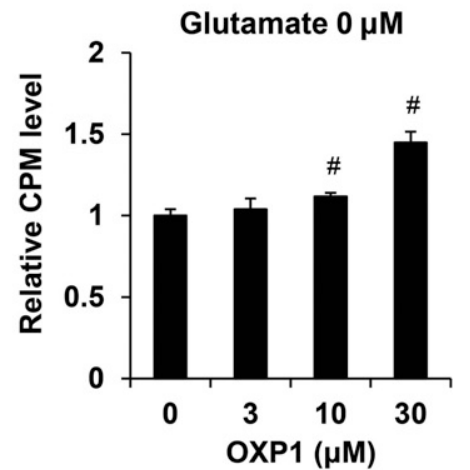

C

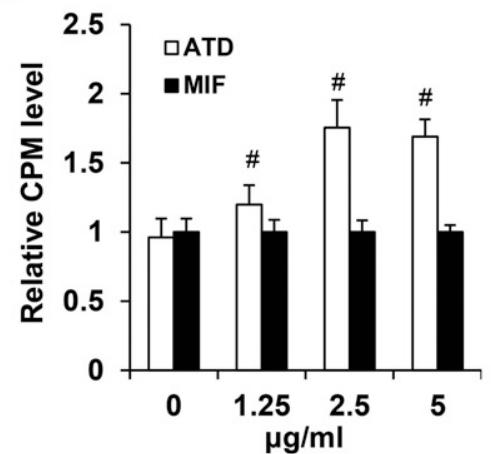

$\mathbf{F}$
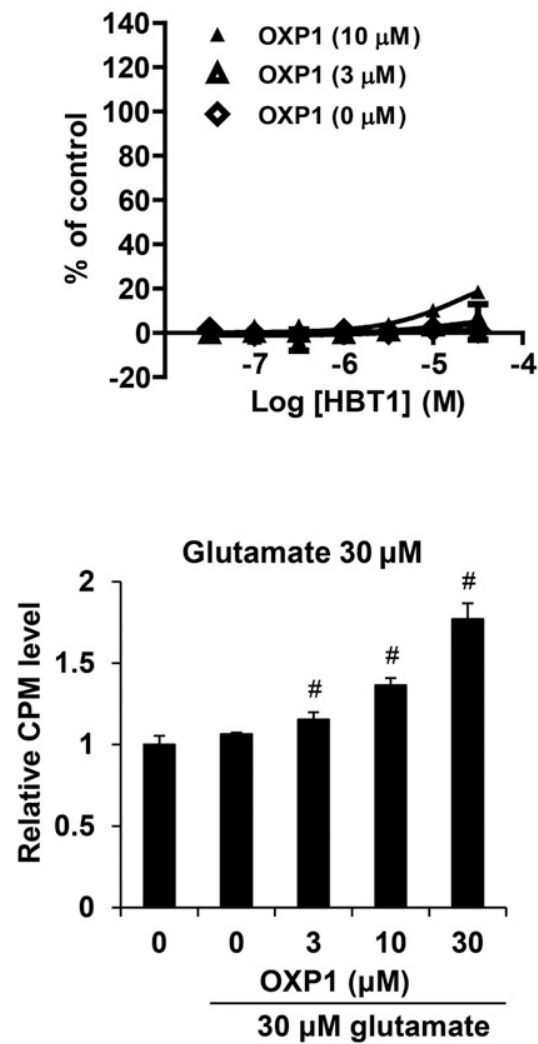

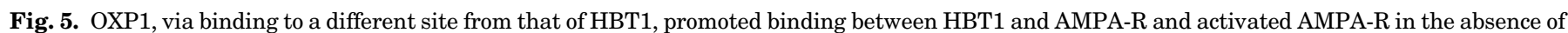

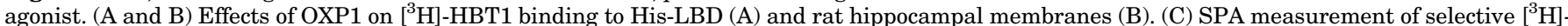

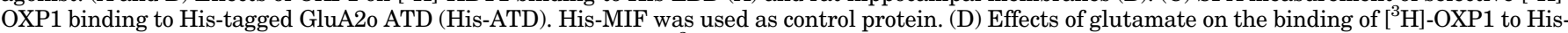

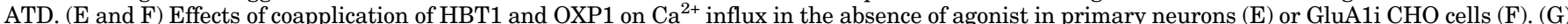

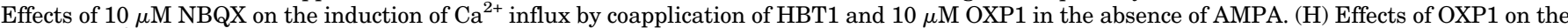

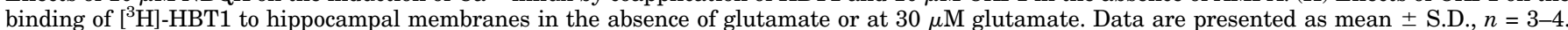

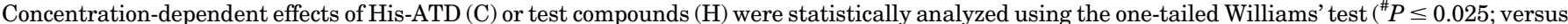
control group).

AMPA-R potentiators. The detailed mechanism of the bellshaped response of LY451395 is unknown. Interestingly, AMPA (pure agonist) did not show a bell-shaped response in the BDNF assay. Thus, agonistic effect by AMPA and AMPA-R potentiators may have different impact on AMPA-Rs and/or their downstream signal transduction machineries. Cells were stimulated with compounds for a long period ( 24 hours) in the BDNF assay, whereas cells were stimulated with compounds for a short period in both the patch-clamp study (30 or 60 seconds) and the $\mathrm{Ca}^{2+}$ influx assay ( 8.5 minutes). Due to this difference, the BDNF assay may have higher sensitivity to detect the bell-shaped responses. Treatment of compounds for a long period might induce desensitization of AMPA-R or its downstream signaling pathways, although further studies are needed.

HBT1 and OXP1 had lower agonistic effects than LY451395 in $\mathrm{Ca}^{2+}$ influx assay using primary neurons. In line with this result, HBT1 showed little agonistic effect in a patch-clamp study using primary neurons. However, OXP1 showed remarkable agonistic effects in a patch-clamp study using 
primary neurons. Binding site of OXP1 seemed to be different from that of HBT1 and would not be located in the LBD. Thus, structural changes caused by OXP1 may differ from that by HBT1. This difference might contribute to difference in structure of pore-forming domain and resulting $\mathrm{Ca}^{2+}$ permeability, although further studies would be needed. AMPA$\mathrm{R}$-mediated BDNF production may depend on increase in intracellular $\mathrm{Ca}^{2+}$ level (Hardingham et al., 1998; Tao et al., 1998; Shieh and Ghosh, 1999). Thus, BDNF production in the absence of AMPA by OXP1 cannot be explained by its agonistic effect observed in the patch-clamp study. OXP1 required lower concentration of glutamate to activate AMPA-R compared with HBT1. Moreover, OXP1 can induce $\mathrm{Ca}^{2+}$ influx in the presence of agonist. Thus, the very low concentration of endogenous glutamate released from the excited primary neuron by OXP1-induced AMPA-R activation would be related to its agonist-like effect in BDNF production. Further studies are needed to understand the detailed mechanism of action of OXP1. Given that the patchclamp study is labor-intensive with a low throughput, both the $\mathrm{Ca}^{2+}$ influx assay and the patch-clamp study may be needed for the screening of AMPA-R potentiators with lower agonistic effects.

Investigation of HBT1 and OXP1 binding sites revealed that HBT1, but not OXP1, bound to the GluA2o LBD. From the X-ray crystallography analysis, HBT1, but not LY451395, formed hydrogen bonds with S518 in the LBD; LY451395 formed hydrogen bonds with P515 and G752 in the LBD. Our results are consistent with the report that LY451646 interacted with P515 and G752 in X-ray crystallography analysis (Kaae et al., 2007; Patel et al., 2013). Thus, amino acid residues used by HBT1 for interaction in the LBD would be different from those used by LY451395, and this difference may be associated with the lower agonistic effect of HBT1. It has been shown that glutamate binding changes the protein structure of the HBT1 site in the LBD (Armstrong and Gouaux, 2000; Yelshanskaya et al., 2014). [ $\left.{ }^{3} \mathrm{H}\right]-\mathrm{HBT} 1$ bound to both His-LBD and rat hippocampal membrane only in the presence of glutamate. On the contrary, $\left[{ }^{3} \mathrm{H}\right]-\mathrm{LY} 395153$, which is an arylpropylsulfonamide, is reported to modestly bind to rat cerebral cortical membranes in the absence of agonist (Zarrinmayeh et al., 2001). LY451395 may also bind to the LBD in the absence of agonist.

The AMPA-R ATD may possess an allosteric modulator site for small molecules, although no AMPA-R ATD ligand has been reported yet (Sukumaran et al., 2011). $\left[{ }^{3} \mathrm{H}\right]-\mathrm{OXP} 1$ seemed to specifically bind to His-ATD in the SPA. This implies that the AMPA-R ATD may have a binding pocket for small molecules, and endogenous AMPA-R ATD ligand may also exist in the brain. However, $\left[{ }^{3} \mathrm{H}\right]-\mathrm{OXP} 1$ had a low binding affinity to His-ATD, and the signal-to-noise ratio was about twofold in the SPA. Moreover, owing to lack of known ATD ligands, it is unclear whether the protein structure of His-ATD used in this study is close to that of physiologic receptors. Further studies are needed to determine whether OXP1 really binds to the ATD. Because it is unknown whether the agonistic property is a common feature of OXP1 site binders, further assessment of compounds with binding affinity to OXP1 site may be worth trying.

To our surprise, costimulation with HBT1 and OXP1 activated AMPA-R in the absence of agonists in primary neurons. AMPA-R activation by costimulation with HBT1 and OXP1, LY451395 (Fig. 2C), or OXP1 (Fig. 3C) was not observed in GluA1i CHO cells in the absence of glutamate.
Therefore, a screening strategy depending on functional assays with AMPA-R expressing artificial cell lines is insufficient, and understanding the binding site of each chemotype is critical for discovery of AMPA-R potentiators with lower agonistic effects. The protein structure of native AMPA-Rs is complicated; native AMPA-Rs are most likely tetramers generated by the assembly of eight subunits (GluAi 1-4, GluAo 1-4) (Nakanishi et al., 1990), and furthermore, the machinery responsible for assembly requires auxiliary accessory transmembrane proteins such as TARPs (Tomita, 2010). Reconstruction of native AMPA-R with these complexities may be difficult, and thus the properties of recombinant AMPA-Rs in general would be critically different from those of native AMPA-R. In fact, a $\mathrm{Ca}^{2+}$ influx assay using a cell line expressing recombinant AMPA-R could not detect AMPA-R activation by glutamate (Miu et al., 2001). Therefore, functional assays using primary neurons would be necessary to identify AMPA-R potentiators with lower agonistic effect, although a screening assay using a large number of primary neurons is not realistic, because it is labor-intensive and also lacks AMPA-R selectivity.

In summary, we have shown some evidence that agonistic effect may be associated with bell-shaped response of AMPA-R potentiators. HBT1, a novel AMPA-R potentiator with lower agonistic effects, had lower risks of bell-shaped response in in vitro BDNF production compared with LY451646, LY451395, and OXP1. Unfortunately, HBT1 has a poor absorption, distribution, metabolism and excretion (ADME) profile and is not suitable for in vivo studies. Discovery and development of novel AMPA-R potentiators with lower agonistic effects like HBT1 may be worth considering. The screening approach using the various binding and functional assays we show in this work (e.g., SPA using $\left[{ }^{3} \mathrm{H}\right]-\mathrm{HBT} 1$ and His-LBD, X-ray crystallographic analysis, $\mathrm{Ca}^{2+}$ influx using cell lines expressing AMPA-R and primary neurons, patchclamp study using primary neurons, BDNF assay) would be important to discover AMPA-R potentiators with lower risks of bell-shaped response. Based on the strategy, we have discovered a clinical candidate, TAK-653, with lower risks of both in vitro and in vivo bell-shaped response (manuscripts in preparation).

\section{Acknowledgments}

We express our sincere thanks to Atsushi Suzuki and Ayumi Kawano for supporting the patch-clamp study; Aki Hirokawa and Shigeru Igaki for providing recombinant proteins; Akihiro Yokota for characterizing protein-ligand interactions; Lane Weston and Gyorgy Snell for supporting the X-ray crystallography analysis; and Michiyo Mochizuki, Shoutarou Miura, and Shogo Marui for providing chemical compounds.

\section{Authorship Contributions}

Participated in research design: Kunugi, Kimura. Conducted experiments: Kunugi, Tajima, Kuno, Sogabe. Performed data analysis: Kunugi, Tajima, Kuno, Sogabe.

Wrote or contributed to the writing of the manuscript: Kunugi, Sogabe, Kimura.

\section{References}

Armstrong N and Gouaux E (2000) Mechanisms for activation and antagonism of an AMPA-sensitive glutamate receptor: crystal structures of the GluR2 ligand binding core. Neuron 28:165-181.

Bai F, Bergeron M, and Nelson DL (2003) Chronic AMPA receptor potentiator (LY451646) treatment increases cell proliferation in adult rat hippocampus. Neuropharmacology 44:1013-1021. 
Balaratnasingam S and Janca A (2012) Brain derived neurotrophic factor: a novel neurotrophin involved in psychiatric and neurological disorders. Pharmacol Ther 134:116-124.

Beattie EC, Carroll RC, Yu X, Morishita W, Yasuda H, von Zastrow M, and Malenka RC (2000) Regulation of AMPA receptor endocytosis by a signaling mechanism shared with LTD. Nat Neurosci 3:1291-1300.

Bernard K, Danober L, Thomas JY, Lebrun C, Muñoz C, Cordi A, Desos P, Lestage P, and Morain P (2010) DRUG FOCUS: S 18986: a positive allosteric modulator of AMPA-type glutamate receptors pharmacological profile of a novel cognitive enhancer. CNS Neurosci Ther 16:e193-e212.

Boulter J, Hollmann M, O'Shea-Greenfield A, Hartley M, Deneris E, Maron C, and Heinemann S (1990) Molecular cloning and functional expression of glutamate receptor subunit genes. Science 249:1033-1037.

Chen VB, Arendall WB, III, Headd JJ, Keedy DA, Immormino RM, Kapral GJ, Murray LW, Richardson JS, and Richardson DC (2010) MolProbity: all-atom structure validation for macromolecular crystallography. Acta Crystallogr D Biol Crystallogr 66:12-21.

Derkach VA, Oh MC, Guire ES, and Soderling TR (2007) Regulatory mechanisms of AMPA receptors in synaptic plasticity. Nat Rev Neurosci 8:101-113.

Ehlers MD (2000) Reinsertion or degradation of AMPA receptors determined by activity-dependent endocytic sorting. Neuron 28:511-525.

Emsley P, Lohkamp B, Scott WG, and Cowtan K (2010) Features and development of coot. Acta Crystallogr D Biol Crystallogr 66:486-501.

Fletcher EJ, Nutt SL, Hoo KH, Elliott CE, Korczak B, McWhinnie EA, and Kamboj RK (1995) Cloning, expression and pharmacological characterization of a human glutamate receptor: hGluR4. Receptors Channels 3:21-31.

Fowler JH, Whalley K, Murray T, O'neill MJ, and McCulloch J (2004) The AMPA receptor potentiator LY404187 increases cerebral glucose utilization and c-fos expression in the rat. $J$ Cereb Blood Flow Metab 24:1098-1109.

Gates M, Ogden A, and Bleakman D (2001) Pharmacological effects of AMPA receptor potentiators LY392098 and LY404187 on rat neuronal AMPA receptors in vitro. Neuropharmacology 40:984-991.

Hardingham GE, Cruzalegui FH, Chawla S, and Bading H (1998) Mechanisms controlling gene expression by nuclear calcium signals. Cell Calcium 23:131-134.

Jhee SS, Chappell AS, Zarotsky V, Moran SV, Rosenthal M, Kim E, Chalon S, Toublanc N, Brandt J, Coutant DE, et al. (2006) Multiple-dose plasma pharmacokinetic and safety study of LY450108 and LY451395 (AMPA receptor potentiators) and their concentration in cerebrospinal fluid in healthy human subjects. $J$ Clin Pharmacol 46:424-432.

Kaae BH, Harpsøe K, Kastrup JS, Sanz AC, Pickering DS, Metzler B, Clausen RP, Gajhede M, Sauerberg P, Liljefors T, et al. (2007) Structural proof of a dimeric positive modulator bridging two identical AMPA receptor-binding sites. Chem Biol 14:1294-1303.

Kato AS, Siuda ER, Nisenbaum ES, and Bredt DS (2008) AMPA receptor subunitspecific regulation by a distinct family of type II TARPs. Neuron 59:986-996.

Keinänen K, Wisden W, Sommer B, Werner P, Herb A, Verdoorn TA, Sakmann B, and Seeburg PH (1990) A family of AMPA-selective glutamate receptors. Science 249:556-560.

Kew JN and Kemp JA (2005) Ionotropic and metabotropic glutamate receptor structure and pharmacology. Psychopharmacology (Berl) 179:4-29.

Mackowiak M, O'Neill MJ, Hicks CA, Bleakman D, and Skolnick P (2002) An AMPA receptor potentiator modulates hippocampal expression of BDNF: an in vivo study. Neuropharmacology 43:1-10.

Miu P, Jarvie KR, Radhakrishnan V, Gates MR, Ogden A, Ornstein PL, Zarrinmayeh H, Ho K, Peters D, Grabell J, et al. (2001) Novel AMPA receptor potentiators LY392098 and LY404187: effects on recombinant human AMPA receptors in vitro. Neuropharmacology 40:976-983.

Murray TK, Whalley K, Robinson CS, Ward MA, Hicks CA, Lodge D, Vandergriff JL, Baumbarger P, Siuda E, Gates M, et al. (2003) LY503430, a novel alpha-amino-3hydroxy-5-methylisoxazole-4-propionic acid receptor potentiator with functional, neuroprotective and neurotrophic effects in rodent models of Parkinson's disease. $J$ Pharmacol Exp Ther 306:752-762.
Murshudov GN, Skubák P, Lebedev AA, Pannu NS, Steiner RA, Nicholls RA, Winn MD, Long F, and Vagin AA (2011) REFMAC5 for the refinement of macromolecular crystal structures. Acta Crystallogr D Biol Crystallogr 67:355-367.

Nakanishi N, Shneider NA, and Axel R (1990) A family of glutamate receptor genes: evidence for the formation of heteromultimeric receptors with distinct channel properties. Neuron 5:569-581.

O'Neill MJ, Bleakman D, Zimmerman DM, and Nisenbaum ES (2004) AMPA receptor potentiators for the treatment of CNS disorders. Curr Drug Targets CNS Neurol Disord 3:181-194

O'Neill MJ and Dix S (2007) AMPA receptor potentiators as cognitive enhancers. IDrugs 10:185-192.

O'Neill MJ and Witkin JM (2007) AMPA receptor potentiators: application for depression and Parkinson's disease. Curr Drug Targets 8:603-620.

Otwinowski Z and Minor W (1997) Processing of X-ray diffraction data collected in oscillation mode. Methods Enzymol 276:307-326.

Patel NC, Schwarz J, Hou XJ, Hoover DJ, Xie L, Fliri AJ, Gallaschun RJ, Lazzaro JT, Bryce DK, Hoffmann WE, et al. (2013) Discovery and characterization of a novel dihydroisoxazole class of $\alpha$-amino-3-hydroxy-5-methyl-4-isoxazolepropionic acid (AMPA) receptor potentiators. J Med Chem 56:9180-9191.

Schoft VK, Schopoff S, and Jantsch MF (2007) Regulation of glutamate receptor B pre-mRNA splicing by RNA editing. Nucleic Acids Res 35:3723-3732.

Shaffer CL, Hurst RS, Scialis RJ, Osgood SM, Bryce DK, Hoffmann WE, Lazzaro JT, Hanks AN, Lotarski S, Weber ML, et al. (2013) Positive allosteric modulation of AMPA receptors from efficacy to toxicity: the interspecies exposure-response continuum of the novel potentiator PF-4778574. J Pharmacol Exp Ther 347:212-224.

Shieh PB and Ghosh A (1999) Molecular mechanisms underlying activity-dependent regulation of BDNF expression. J Neurobiol 41:127-134.

Sobolevsky AI, Rosconi MP, and Gouaux E (2009) X-ray structure, symmetry and mechanism of an AMPA-subtype glutamate receptor. Nature 462:745-756.

Sommer B, Keinänen K, Verdoorn TA, Wisden W, Burnashev N, Herb A, Köhler M, Takagi T, Sakmann B, and Seeburg PH (1990) Flip and flop: a cell-specific functional switch in glutamate-operated channels of the CNS. Science 249: 1580-1585.

Sukumaran M, Rossmann M, Shrivastava I, Dutta A, Bahar I, and Greger IH (2011) Dynamics and allosteric potential of the AMPA receptor N-terminal domain. EMBO J 30:972-982

Tao X, Finkbeiner S, Arnold DB, Shaywitz AJ, and Greenberg ME (1998) Ca2+ influx regulates BDNF transcription by a CREB family transcription factor-dependent mechanism. Neuron 20:709-726.

Tomita S (2010) Regulation of ionotropic glutamate receptors by their auxiliary subunits. Physiology (Bethesda) 25:41-49.

Vagin A and Teplyakov A (2010) Molecular replacement with MOLREP. Acta Crystallogr D Biol Crystallogr 66:22-25.

Ward SE, Bax BD, and Harries M (2010) Challenges for and current status of research into positive modulators of AMPA receptors. Br J Pharmacol 160:181-190.

Winn MD, Ballard CC, Cowtan KD, Dodson EJ, Emsley P, Evans PR, Keegan RM, Krissinel EB, Leslie AG, McCoy A, et al. (2011) Overview of the CCP4 suite and current developments. Acta Crystallogr D Biol Crystallogr 67:235-242.

Yamada KA (1998) Modulating excitatory synaptic neurotransmission: potential treatment for neurological disease? Neurobiol Dis 5:67-80.

Yelshanskaya MV, Li M, and Sobolevsky AI (2014) Structure of an agonist-bound ionotropic glutamate receptor. Science 345:1070-1074.

Zarrinmayeh H, Bleakman D, Gates MR, Yu H, Zimmerman DM, Ornstein PL, McKennon T, Arnold MB, Wheeler WJ, and Skolnick P (2001) [3H]N-2-(4-(Nbenzamido)phenyl)propyl-2-propanesulfonamide: a novel AMPA receptor potentiator and radioligand. $J$ Med Chem 44:302-304.

Address correspondence to: Dr. Haruhide Kimura, CNS Drug Discovery Unit, Research, Takeda Pharmaceutical, 26-1, Muraoka-higashi 2-chome, Fujisawa, Kanagawa 251-8555, Japan. E-mail: haruhide.kimura@takeda.com 